\title{
Los estudios regionales contemporáneos; legados, perspectivas y desafíos en el marco de la geografía cultural ${ }^{1}$
}

\section{Contemporary regional studies: legacies, perspective and challenges in the framework of cultural geography}

\author{
Ryszard EdWard Rózga-Luter* \\ Celia Hernández-Diego**
}

\begin{abstract}
The main objective of this work is to analyze the legacies, perspectives and challenges to the concept of region in the framework of contemporary regional studies and of cultural region. We consider some general and particular definitions circumscribed to the region word, taking into account three main approaches: the chorological, the regional science and the contemporary social and cultural interpretations of region. Other intention of this work points at recognizing that the concept of region nowadays exhibits a series of perspectives and challenges that become a must in the general analysis of space.
\end{abstract}

Keywords: region, space, cultural geography.

\section{Resumen}

El objetivo principal de este trabajo es analizar los legados, perspectivas y desafíos del concepto de región en el marco de los estudios regionales contemporáneos y de la geografía cultural. Se consideran algunas definiciones generales y particulares circunscritas al vocablo región, tomando en cuenta tres enfoques principales: el crológico, el de la ciencia regional y las interpretaciones sociales y culturales contemporáneas sobre la región. Otra intención del trabajo apunta a reconocer que el concepto de región presenta hoy una serie de perspectivas y desafíos que se vuelven un imperativo en el análisis general del espacio.

Palabras clave: región, espacio, geografía cultural.

${ }^{1}$ Ésta es una versión corregida del trabajo presentado en el $14^{\circ}$ Encuentro Nacional sobre Desarrollo Regional en México, Amecider 2009, realizado en la Universidad de Guanajuato, Campus León, 10-13 de noviembre de 2009.

* Universidad Autónoma Metropolitana, Xochimilco, y Universidad Autónoma del Estado de México. Correos-e: rrozga@correo.xoc.uam.mx, rrozga@uaemex.mx.

** Universidad Autónoma Metropolitana, Xochimilco. Correo-e: cehedi@correo.xoc.uam.mx. 


\section{Introducción}

Actualmente, los estudios regionales contemporáneos muestran que es mucho más fácil explicar las disparidades regionales analizando los factores culturales, y no sólo utilizando parámetros cuantitativos o disciplinares puros. De modo que, lejos de ser una variable aislada en la transformación de los espacios, la cultura se vuelve entonces una constante que atraviesa el espectro de la experiencia social en cualquiera de sus expresiones. Por tanto, además de ser históricamente reconocida como una categoría económica y social, ahora la región también se destaca por las cualidades culturales que la definen. Esta condición invita a redefinir y explorar conceptos, métodos y perspectivas teóricas en torno a la idea de región. Entre los legados de esta idea aparecen de manera recurrente categorías homogeneizantes y totalizadoras. Sin embargo, con el paso del tiempo se han empezado a reconocer los procesos difusos que se dan en el espacio social y, por ende, en los espacios regionalizados. Así, el debate se ha replegado y expandido en un vaivén de construcciones argumentativas exacerbantes. Los intentos de síntesis se desdibujan ante el entramado conceptual y metodológico que rebasa los estudios territoriales que se han hecho hasta ahora. En este sentido, abundan las percepciones interdisciplinares que analizan la naturaleza, dimensión y alcance de la región, y la forma de aprehenderlas ante la transformación del espacio.

En concreto, los estudios regionales contemporáneos no buscan únicamente cómo describir las peculiaridades y distinciones regionales, sino también tratan de interpretar las características del ambiente cultural local en relación con los retos que en la actualidad representan los procesos globales. Esto nos lleva a un análisis pertinente surgido de la filosofía, de la ciencia contemporánea acerca de las relaciones entre los casos particulares y las leyes universales, así como al debate sobre la pertinencia de los métodos cuantitativos y cualitativos que definen la praxis de actores individuales y colectivos en un ámbito regional. Además de reconocer que la región es un referente que se ha moldeado y enriquecido con los desarrollos y miradas heterogéneas de actores esparcidos en diferentes contornos. Estos intereses han desbordado las fronteras epistemológicas en las cuales se ha analizado la idea de las escalas, procesos y dinámicas como elementos inherentes a la noción de región. Al no ser entendida como algo estático, la región experimenta un desdoblamiento que se abre a transiciones cualitativas y cuantitativas de distinto orden.

El rasgo esencial de la regionalización se cimenta en un ejercicio delimitativo centrado en cuestiones geográficas, culturales, perceptivas, políticas o económicas que se entrecruzan o definen a partir del juego individual y colectivo de lo social. Ello implica introducirse en la génesis, 
desarrollo, arraigo, reproducción o desaparición de un espacio que se circunscribe conceptual, perceptual, jurídica o metodológicamente sobre límites difusos. Por un lado, la región ha sido el resultado de intentos históricos por potenciar las capacidades, recursos o actividades de un determinado lugar. Pero también, se ha pretendido que la región incluya en su cuerpo de análisis la idea de integración en redes más dinámicas y en diferentes escalas. Estas ideas sobre regionalización han configurado la historia y el mapa mundial que hoy se tiene. En estos términos, la región sería reconocida no sólo como un objeto central en las formas georreferenciadas en la historia de los territorios, sino como la base para entender los procesos del regionalismo contemporáneo y de la propia transición de las economías locales y mundiales. Una perspectiva que ha prestado una significativa atención a estos cambios es en especial la geografía cultural surgida en los albores del siglo xx.

En sus inicios, la geografía cultural intenta abolir la disociación entre la geografía física y la geografía humana. En este marco, se ha retomado al espacio como objeto de reflexión que reclama una visión integral del mundo, dividida varios siglos atrás por la ciencia. En este cometido, el espacio se hace patente como fundamento de la acción misma del ser humano y evidencia una necesidad de integración plena. Así, el panorama de los estudios regionales se expande en un prisma inconmensurable e inédito. El imperativo es encarar las transformaciones ligadas a los cambios industriales, comerciales, políticos, urbanos, rurales, de crisis económica y social. Sin dejar de reconocer que en todo momento la fuerza avasallante de estos fenómenos hilvana los espacios locales y mundiales. En todo esto hay una lectura que se orienta a reconocer los procesos reticulares a los que se somete el mundo contemporáneo. En esta reflexión tiene cabida la problemática del calentamiento global, el agua, las guerras, la inequidad económica y tantos otros temas pendientes en la agenda de académicos, políticos y de quienes toman decisiones. Condiciones que amenazan la estabilidad de regiones locales y del mundo. Es aquí donde el estudio de la región revive y cobra un sentido más integrador del análisis geográfico.

Por lo anterior, este trabajo tiene como objetivo principal analizar los legados, perspectivas y desafíos del concepto de región en el marco de los estudios regionales contemporáneos y de la geografía cultural. Para ello, se considera en primer término la sucesión de definiciones generales y particulares circunscritas al vocablo región, tomando en cuenta tres enfoques principales: el corológico, el de la ciencia regional y, finalmente, las interpretaciones sociales y culturales contemporáneas sobre la región. Otra intención de este trabajo apunta al reconocimiento de que el concepto de región, al nutrirse históricamente de categorías y cuerpos teóri- 
cos de distintas disciplinas, presenta hoy una serie de perspectivas y desafíos que se vuelven un imperativo en el análisis general del espacio. Esta condición es todavía más apremiante al constituirse como un ejercicio crítico en los estudios territoriales frente a los cambios, estados y vicisitudes que se han llevado a cabo en la región y sus agentes transformadores. Por ello, resulta necesario tomar en cuenta que la región es un objeto con ligas entre la historia de los territorios y sus actores, los cambios del presente y las propias expectativas de crecimiento o desarrollo de diferentes unidades geográficas y sociales. En efecto, se insiste en explorar otros modos de aprehensión del espacio, signados en el presente por flujos, redes y sistemas, cuya espacialidad se desplaza junto con los actores sociales que la crean. Hay desde luego un reto que se empieza a construir desde los estudios territoriales -en particular en la geografía cultural- para reconocer las categorías, premisas y estados que dibujan una idea de región distinta y acorde con los cambios que se tienen de frente. Se apuesta entonces por entender la región como un referente en el que se reconocen procesos caóticos, heterogéneos, segmentados y de fronteras difusas; cuya problemática, evidentemente, obliga a repensar sus enigmas a partir de modos alternos.

\section{Legados de la idea de región}

Todo objeto de conocimiento tiene una naturaleza de vínculos y conexiones que lo definen en su condición cognoscente y expresión pragmática. Es decir, los modos de aprehender un objeto se moldean a partir de un juego interactivo de categorías, metodologías y teorías en resonancia permanente que remiten a una naturaleza relacional $y$, por ende, siempre en interacción. De igual modo, con la plataforma de la experiencia, los actores, agentes o condiciones se intervienen mutuamente en un vasto entramado de relaciones sobre un denso espacio de sucesos y vivencias. A partir de esta perspectiva, nada está aislado y nada puede ser comprendido sino a partir de entender los vínculos que lo constituyen. En una extrapolación al campo de lo social, sería imposible entender las transformaciones pasadas y vigentes sin remitirse a las condiciones de vinculación, intercambio o transacción que las definen. Tampoco podría entenderse lo social sin remitirse a sus formas geográficas, tanto históricas como vigentes. Finalmente, el espacio no puede entenderse sino como una marańa de relaciones entre seres humanos, territorios y tiempos.

Desde tiempos inmemoriales, el ser humano ha intentado alcanzar los linderos del mundo, al mismo tiempo ha tratado de circunscribir su experiencia a formas y referentes geográficos de múltiples maneras. Para ello, se ha valido de los íconos tomados de la naturaleza y de su entorno 
y de las delimitaciones creadas por otros hombres. Estas referencias algunas veces fueron sesgadas por temores, prejuicios e imaginarios. De esto hay ejemplos en diferentes puntos de la historia. En el mundo antiguo, además de los imperios de Caldea, India y Egipto, ${ }^{2}$ se reconocen los escritos de China, ${ }^{3}$ Grecia y Roma por destacar de forma especial en sus aportes a la ciencia geográfica mundial. Particularmente, en la antigua Grecia el saber geográfico ${ }^{4}$ se cimentó a partir de la formalización de conocimientos transmitidos de generación en generación, del saber que se iba atesorando con cada nuevo movimiento colonial, militar y mercantil y con la incipiente reflexión filosófica que se hacía sobre el entorno en el que el ser humano desarrolla su experiencia vital (Paniagua, 2006: 150). En su obsesión por entender el mundo, los griegos mostraron siempre un interés inacabado por armar el rompecabezas geográfico de pueblos, ciudades y paisajes. En esta tarea muchas veces llegaron a fusionar las fron-

${ }^{2}$ En Egipto, el sentido de la geografía se proyectó en su concepción del mundo basada en la dualidad orden/caos. Con esta perspectiva, "todo aquello que es ajeno y estaba fuera de la llanura aluvial es caótico y representa una amenaza para el mantenimiento del orden que los dioses establecieron en la creación" (Pérez, 2006: 42). Sin embargo, estas ideas fueron cambiando al contacto con "lo 'exterior' y el conocimiento de otras culturas avanzadas" (idem). La imagen geográfica de Egipto llegó a definirse en concordancia con "los fenómenos naturales, llegando en el sur hasta donde alcanzan los vientos del Norte -los únicos existentes en Egipto-y, en el norte, hasta el Mediterráneo, pero en el Reino Medio los límites del mundo, que no del orden, se definen con expresiones que permiten englobar la flexibilidad de las fronteras; hasta donde el sol abarca o hasta donde se sitúan los cuatro pilares sobre los que se sustenta el cielo" (idem).

${ }^{3}$ También en los primeros escritos chinos sobre geografía se reconoce una visión corográfica del mundo donde destacan algunos pueblos, mares, ríos y montańas. Estas ideas nutrieron la figura mítica del gobernador Huella Reptante (Yu) y la gran inundación; personaje que sobresale como salvador de dos acontecimientos: pone fin a la inundación y limpia la tierra de polución (Birrell, 2005: 41). Birrell también dice que "algunas narraciones mitológicas describen su itinerario por el mundo mítico de las Nueve Provincias, situadas en el interior de los Cuatro Mares. Según esos relatos, a medida que Yu, en sus labores de control de la inundación, cruzaba ríos y montañas, cartografió la tierra y apuntó los nombres de las tribus locales y sus costumbres" (2005: 60). El testimonio de los antiguos libros chinos coinciden en la labor de reconocer la existencia de numerosos pueblos, tribus y dinastías, origen étnico, condiciones políticas, establecidos cerca del territorio de los Estados Shang, Zhou y Han en el periodo comprendió entre c. 1700 a. C. y 200 d. C. (Birrell, 2005: 41). Particularmente, durante la dinastía Han, c. 100 a. C., se produjo el envío de las primeras embajadas chinas a tierras extranjeras; misiones que dejaron testimonio escrito de sus experiencias y relatos sobre las costumbres, el aspecto, la lengua y los nombres de pueblos foráneos, los cuales fueron incorporados a los primeros anales históricos (Birrell, 2005: 60). En general la visión cosmológica de los chinos se encuentra llena de relatos vinculados con su naturaleza geográfica; en ellos aparecen plantas, animales, montañas y espacios infinitos; relatos que coincidían con el testimonio de exploradores de la época, sin dejar de reconocer que también había narraciones prejuiciadas de mentes fantasiosas que ofrecían relatos distorsionados "de los pueblos con los que se encontraron o de los que oyeron hablar más allá de las fronteras de la civilización china" (idem). Debe quedar claro que estas últimas impresiones "pertenecen a la mitología antes que a la historia" (idem).

4 "El saber geográfico de los griegos está presente en su literatura desde las más tempranas manifestaciones. La presencia en el 'epos' homérico, tanto en la Ilíada como en la Odisea, de un componente geográfico ampliamente desarrollado testimonia su protagonismo en épocas anteriores y subraya el interés y la centralidad de la geografía en la sociedad griega homérica" (Paniagua, 2006: 150). En el Libro de los Muertos aparecen un sinnúmero de lugares geográficos y mitológicos que dan cuenta del sentido del espacio para los egipcios (Budge, 2007: 153-158). 
teras de lo mitológico con las experiencias de viajeros, comerciantes, escritores y cronistas del aquel entonces. ${ }^{5}$ Ejemplos invaluables de ello fueron el Catálogo troyano ${ }^{6}$ y el Catálogo de los aqueos (griegos) ${ }^{7}$ que aparecen en el libro II de la Ilíada de Homero ${ }^{8}$ y las Historias de Herodoto. ${ }^{9}$ De igual manera, los griegos dieron nombre a la palabra geografía y también fueron los primeros que intentaron una orientación de los conocimientos geográficos (Redondo, 2007: 24). Un incentivo para que esto sucediera fueron las conquistas por mayores espacios con miras estratégicas, militares, políticas o comerciales, las cuales obligaron a los griegos a reflexionar y emprender expediciones de investigación geográfica (Paniagua, 2006: 151). Esta preocupación no sólo la compartían los emperadores, generales o pensadores de la época, pues "a medida que se ensanchaba el campo de acción de griegos y romanos, algunos escritores se vieron también impulsados a ampliar sus conocimientos geográficos" (Redondo, 2007: 24). En forma simultánea, se hicieron algunas reflexiones sobre la naturaleza esférica de la Tierra, tamaño, forma, posición en el espacio, condiciones físicas, distribución de aguas y tierras, inventarios de plantas, animales y habitantes en cada territorio (idem). De estos ejercicios nació el primer planisferio y sus posteriores diseños mejorados, también algunos tratados, monografías, obras etnográficas y paradoxográficas acerca de la forma de la tierra, la disposición geográfica de las regiones, los océanos, las islas, los límites, las distancias, etcétera (Paniagua, 2006: 165).

En su afán de exploración y de entendimiento del mundo, los griegos desarrollaron y sistematizaron un conocimiento ordenado sobre el conjunto de fenómenos que atañen a la tierra de dos maneras diferentes: 1) como descripción y estudio de toda la Tierra en su totalidad y como

\footnotetext{
${ }^{5}$ Los relatos históricos de los griegos, al igual que en otras culturas, no siempre fueron tratados con rigor, ya que era frecuente que las narraciones se hicieran más a título personal que por una práctica estricta de investigación. En muchos casos, "los investigadores griegos se ganaban su reputación más bien impresionando a su propio grupo social o a la ciudadanía en su conjunto" (Lloyd, 2008: 17-18). Para ello no dudaban en distorsionar los relatos históricos o desprestigiar el trabajo de sus homólogos. Esto debido al contexto altamente competitivo de la vida intelectual griega, en el que muchos eran los que pretendían proclamar el carácter especial de su conocimiento frente a los rivales o colegas (Lloyd, 2008: 80, 25)

${ }^{6}$ Éste fue uno de los primeros intentos por describir el mundo que rodeaba a Grecia, particularmente consideraba un vago conocimiento de las regiones de Asia Menor que se extendían más allá de la Tróade, en él se describen pocas ciudades, pero en cambio se revelaban elementos naturales como ríos, montañas e incluso un lago (Gómez, 2005: 165).

${ }^{7}$ También conocido como el Catálogo de las naves porque menciona los guerreros con el número de embarcaciones que fueron a Troya (Bocchetti, 2006: 123, cursivas propias).

${ }^{8}$ Según lo que menciona Bocchetti, "una peculiaridad de los catálogos de la Ilíada es que empiezan con zonas urbanas; se mencionan muchas ciudades y a medida que avanza, la descripción se empieza a distanciar de las ciudades y centra su atención en zonas naturales y lugares donde el paisaje es más remoto e impresionante" (Bocchetti, 2006: 124).

${ }^{9}$ El compendio de Historias de Herodoto fue compuesta a mediados del siglo v a. C. y su descripción constituye un verdadero panorama del mundo en aquellos tiempos, así como un testimonio del estado de los conocimientos geográficos griegos en plena época clásica (Gómez, 2005: 177).
} 
parte integrante del Universo, y 2) como entendida en sí misma, sobre todo su superficie, como morada del ser humano (Redondo, 2007: 25). De esta manera los griegos dieron a conocer con detalle rutas, ubicaciones, climas, costumbres y modos de vida de la época, asimismo, sentaron las bases genealógicas de la geografía, dando lugar a la geografía general y a la geografía descriptiva o regional, dualismo que permanece hasta tiempos contemporáneos (idem). Es necesario aclarar que la necesidad de reconocer los laberintos y recovecos del mundo no fue exclusiva de los griegos, pues en todas partes de la historia del ser humano hay ejemplos de cómo los pueblos daban cuenta de su entorno. Acerca de este hecho se han encontrado papiros, mapas, cartografías y dibujos que varían desde formas simples hasta formas sofisticadas de referencia. En ellas se modelaron, además de puntos naturales de referencia (desiertos, montañas, ríos, mares), unidades espaciales (comarcas, pueblos, reinos, Estados), espacios de tránsito (brechas, caminos, rutas de comercio, zonas seguras y peligrosas) e imaginarios de la época (mundos míticos, zonas de extrema riqueza, espacio de dioses y demonios).

De algún modo, las divisiones, directrices y concepciones del espacio se fueron complejizando debido al trabajo de filósofos, matemáticos, cartógrafos, escritores, cronistas, astrónomos, astrólogos e historiadores de todas las épocas. Sin embargo, en este cometido destaca nuevamente de forma especial el papel de los pensadores griegos. ${ }^{10}$ Es en este contexto donde nace la idea de región. Como vocablo, la región surgió en el marco de las lenguas romances, su origen proviene de la tradición romana de la regio (que a su vez viene de régere: gobernar, dominar, regir) (Taracena, 2008: 186). En específico, hay quien señala que el vocablo latino regio parece haber significado originariamente dirección y línea limite, así como área, zona o división espacial en sentido amplio (García, 2006: 28). Pero cuando a la idea de región se le asocia con el verbo regere, entonces asume también un significado político o administrativo (García, 2006: 28); concepción que en el pasado fue explotada sobre todo por delegados del poder central romano (Taracena, 2008: 186), tanto a escala intraurbana como para designar las 13 unidades en las que el Imperio romano organizó la provincia de Italia para efectos fiscales y censales (García, 2006: 28). En un sentido muy parecido, es común encontrar que la idea de región también se adscriba a la raíz latina regius (de rex, regis: el rey), cuyo derivativo más cercano es regio, regir, reino o real (Ma-

${ }^{10}$ Como ejemplo se pueden mencionar algunos griegos que destacaron como: Tales de Mileto (660-585 a. C.), Anaximandro (610-546 a. C.), Hecateo de Mileto (550 a. C.-476 a. C.), Parménides de Elea (530-515 a. C.), Pitágoras (582-497 a. C.), Herodoto (484-425 a. C.), Aristóteles (384-322 a. C.), Aristarco de Samos (310-230 a. C.), Arquímedes (287-195 a. C.), Eratóstenes (276-195), Hiparco de Nicea (190-120 a. C.), Estrabón (64-25 a. C.), Claudio Ptolomeo (ca. 100-170 d. C.). 
teos, 2003: 308), lo cual denota un territorio propio de lo real o de la realeza, es decir, un territorio que conlleva la idea de poder político (Delgadillo, 2003: 37). En este contexto, la noción de región coincide más con la visión de ser un territorio administrativo, que una referencia descriptiva del medio físico-geográfico. El sentido territorial, con todas sus referencias, imaginarios y expresiones espaciales, se le daría sólo varios siglos después.

Hay quienes señalan que las primeras prácticas para delimitar el espacio estuvieron presentes por lo menos desde principios del siglo XVIII (Poche, en Taracena, 2008: 187). Aunque la discusión ontológica empezó propiamente a lo largo de toda la historia moderna; periodo en el que se produjo una serie de debates acerca del territorio a partir de diversas perspectivas de pensamiento. Sin embargo, algunas referencias señalan que el punto más intenso se dio durante el siglo XIX, incluso, hay quien llega a defender la idea de que las concepciones del mundo subyacentes en el quehacer geográfico anterior al siglo XIX, nada tenían que ver con el derivado de las relaciones ser humano-medio defendido en la actualidad por los geógrafos de todas las escuelas (Fernández, 1988: 28). En el siglo XIX se darían a conocer términos como regional (1848) y regionalismo (1875) (Taracena, 2008: 186) y geografía regional ${ }^{11}$ (García, 2006: 28). $\mathrm{El}$ interés se prolongó durante todo el siglo $\mathrm{xx}$, dando como fruto la aparición del calificativo regionalista (1906) y concepciones de ordenamiento como regionalizar (1929) y regionalización (1965) (Taracena, 2008: 186). En este transitar se abrieron amplios debates en Europa, particularmente en Francia, Reino Unido y Alemania. También se escuchó la voz de algunos adeptos críticos en América, sobre todo en Estados Unidos. En este punto hay que reconocer que la tradición histórica para describir y seccionar el mundo en regiones logró la institucionalización de materias como la corografía, ${ }^{12}$ la cartografía y la geografía. Términos que históricamente se han enriquecido con la formalización metodológica de diferentes plataformas de las ciencias y con las remembranzas escri-

\footnotetext{
${ }^{11}$ El enfoque de la geografía moderna primaría los órdenes y configuraciones espaciales sobre cualquier otra explicación de la dinámica social. Además de que las primeras concepciones definidas por la geografía moderna estarían enmarcadas por las totalidades orgánicas humboldtianas y en el todo ritteriano, cuyas concepciones tienen en común la consideración de un objeto holista y teleológico (Fernández, 1988: 28). Así, “mientras las 'totalidades orgánicas' estarían caracterizadas por la interrelación dinámica de los elementos que las componen y por el carácter generalizable de dichas interrelaciones, el 'todo' ritteriano que tendría igualmente un carácter holista y teleológico, estaría constituido por unidades sintéticas, únicas e irrepetibles, resultantes del proceso histórico particular característico de cada una de ellas" (idem).

${ }^{12}$ Esta idea ya aparece en el libro Geografía moderna de 1779 como chrografia y se define de manera general como la "descripción de un país o una provincia" (De la Croix, 1779: 66).
} 
tas o divulgadas de viajeros, estudiosos del tema ${ }^{13} \mathrm{y}$ por aquéllos que, sin pensarlo demasiado, terminaron dando su testimonio o incidiendo directamente en la historia geográfica del mundo. Parte de estos antecedentes sobre la región se plasman en el cuadro 1 .

De acuerdo con algunos detalles, vale la pena señalar que en la segunda mitad del siglo XIX, el pensamiento geográfico se vio trastocado por las propias tendencias cuestionadoras de la época; la cual coincide con la consolidación de la geografía como disciplina, mientras se reconoce ampliamente la relación ser humano-medio en la transformación de los territorios. En este marco se cuestionan los principios de la geografía en relación con el binomio de los problemas físicos y humanos; valorándose, asimismo, tanto los estudios de la naturaleza como culturales. En todo esto tuvo gran influencia la filosofía positivista del siglo XIX, que en la geografía se presenta como un "determinismo de marcado corte ecologista, y una solución para superar la separación que existía entre la geografía física y la humana" (Estébanez, 1986: 47, en Santarelli y Campos, 2002: 37). Una de las razones que las separaba era que sólo la geografía física alcanzaba la categoría de científica (idem), pues era la única cuyas hipótesis se podrían aprobar con los procedimientos de verificación que existían (Santarelli y Campos, 2002: 37). Posterior a esto, se vislumbran las convicciones anarquistas, críticas o radicales de la geografía, cuya propuesta rompía con el discurso consensuado del espacio geográfico como mero elemento físico. Entre los desacuerdos persistentes de la geografía radical sobresale la visión reduccionista del espacio a sólo elementos paisajísticos. En su afán por ampliar la perspectiva de los estudios geográficos, los geógrafos anarquistas ${ }^{14}$ intentaron evidenciar las disparidades, contrastes y heterogeneidades del espacio geográfico. También apostaron por una concepción renovada del espacio a partir de las problemáticas sociales, económicas, políticas y territoriales en una relación más integral entre el ser humano y la naturaleza. Una de las propuestas que salió al paso vino de la geografía cultural.

La geografía cultural se acunó y difundió durante los años veinte, primero en Alemania por Siegfried Passarge, cuya perspectiva estaba en

\footnotetext{
${ }^{13}$ Entre los personajes históricos que no pueden dejar de citarse por el legado que significó para los estudios regionales, está Alexander von Humboldt con el Ensayo político sobre la Nueva España o los 30 volúmenes de Viaje a las regiones equinocciales de América (1804-1827) (Taracena, 2008: 186); así como los trabajos pioneros de Hebertson (1950), Fawcett (1919) y De Blanche (1926) (en Pike, 2007: 1143).

${ }^{14}$ En un periodo de casi 20 ańos (1875-1894), el geógrafo anarquista Élisée Reclus escribe una de las más notables obras en la historia de esta disciplina titulada Geografía universal en 19 volúmenes. El mundo, desde la visión de Reclus, "no es un mundo en fragmentos [...] es un mundo complejo, contrastado, pero unificado por grandes procesos centrales [y, sobre todo, diverso]; la diversidad Reclus la enumera, la describe y la asocia a la idea fundamental del papel del individuo como base de la construcción del desarrollo" (Hiernaux, 1999: 15).
} 


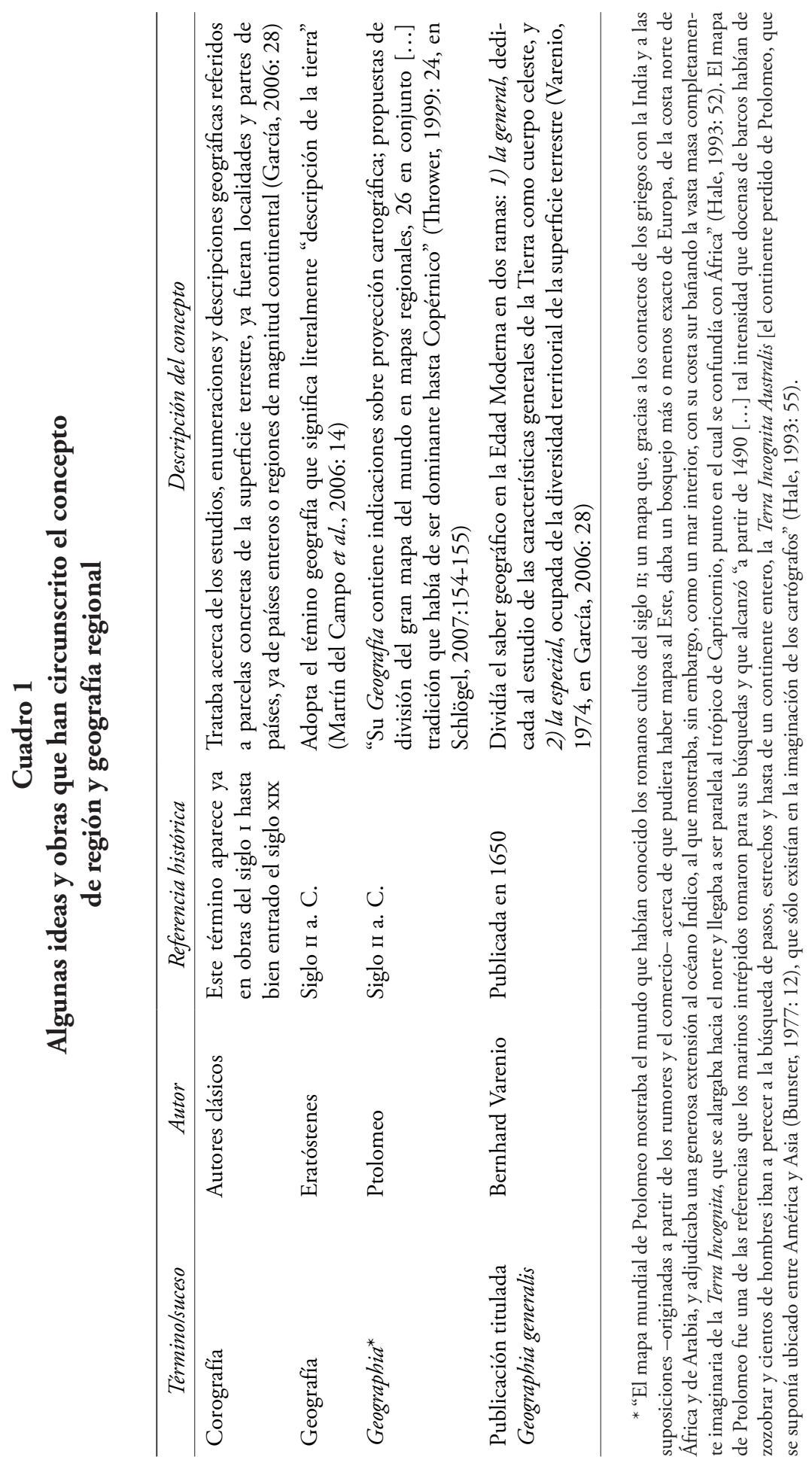




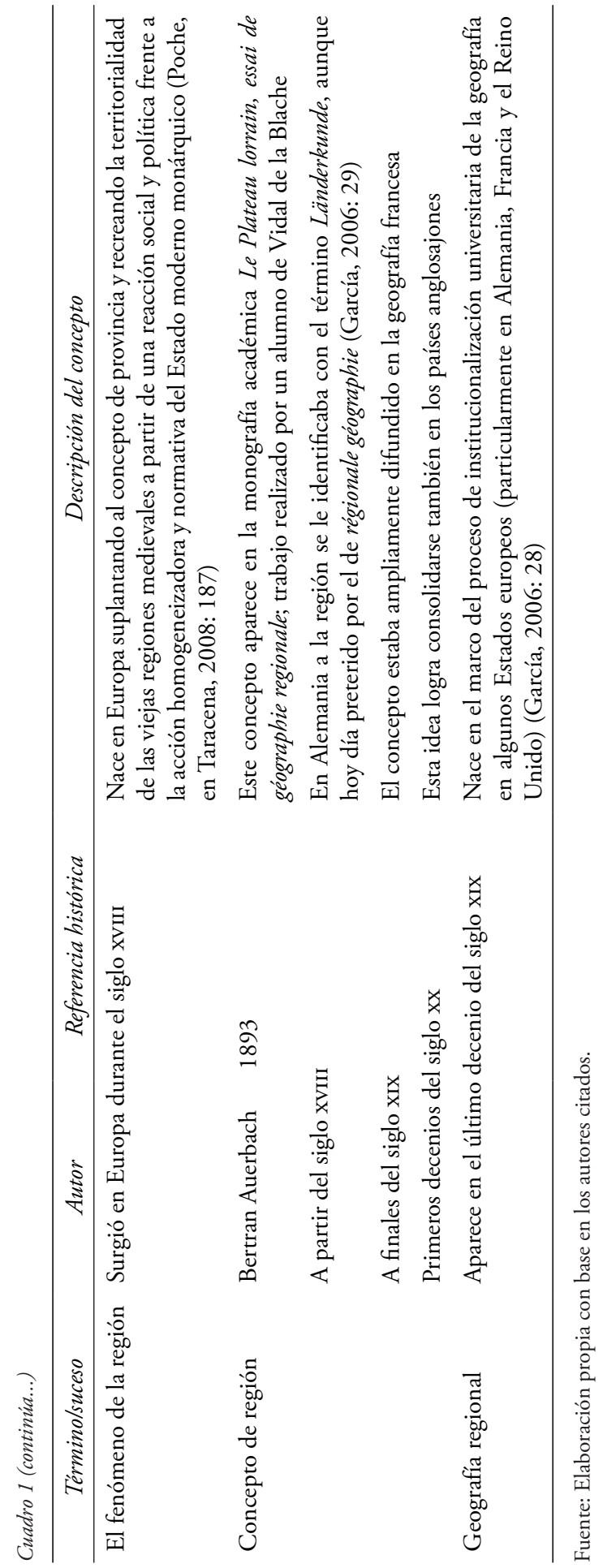


torno al concepto de Kulturgeographie, y por Carl O. Sauer en Estados Unidos con la idea de cultural geographie (Capel, 1989: 33). En el ámbito anglosajón la geografía cultural se gestó al lado de la geografía conductista; ambas orientaciones surgieron en conexión con los cambios epistemológicos y metodológicos originados por la corriente cuantitativa que, a su vez, desembocan en la aparición de las llamadas nuevas geografías (Capel, 1981, y Capel Urtega, 1982, en Gil, 2002: 39). Sauer fue el máximo representante de la geografía cultural en Estados Unidos y quien, a su vez, fue una influencia decisiva para toda una generación de geógrafos, los cuales se llegarían a identificar como la Escuela Californiana (HoltJensen, 2009: 74). Sauer dirigió su principal enfoque de investigación a "una apreciación más activa de la transformación social del espacio" (Jackson, 1989: 15, en Holt-Jensen, 2009: 75). Este autor también se vio atraído por los temas relacionados con "los aspectos materiales de la cultura, particularmente el paisaje"15 (Mitchell, 2000: 21). Para Sauer, un trabajo de investigación tenía que cumplir rigurosamente con "dos cuestiones metodológicas que no debían perderse de vista: la primera consistía en entender al paisaje como un objeto físico y la segunda implicaba hacer [...] un riguroso trabajo de campo" (Fernández, 2006: 223). En algunos de sus trabajos se le reconoció una clara influencia de autores clásicos como Ritter, Humboldt y Ratzel, ${ }^{16}$ además de otros autores alemanes como Otto Schlüter (1872-1952), Alfred Hettner (1859-1941), August Meitzen (1822-1910), Hermann Wagner (1840-1929), Eduard Hahn (1856-1928) y Siegfried Passarge (1867-1958) (Fernández, 2006: 221). El trabajo pionero de Sauer fue el ensayo titulado The morphology of landscape en 1925 (Mitchell, 2000: 20), donde destacó que "el objeto del enfoque morfológico debería ser el estudio del 'contacto del hombre con su cambiante hogar, expresado por el paisaje cultural' y que de manera más general, la interrelación entre grupos y culturas tal como se expresa en los diferentes paisajes del mundo" (Capel, 1989: 35). Pero fue hasta seis años después cuando Sauer declaró en detalle sus ideas sobre

\footnotetext{
${ }^{15} \mathrm{El}$ análisis del paisaje se conoció en el ámbito anglosajón como landscape, cuyos antecedentes más lejanos se encuentran en Wimmer en 1885 en su Historische Landschaftkunde, pero que sólo se hizo popular después de 1906 con la exposición de Otto Schlüter (Dikshit, 2006: 79). Aunque incluso hay quien apunta que el interés por el paisaje viene del siglo XvI en la tradición paisajística del Renacimiento; época de florecimiento de pintores y artistas europeos que se interesaron en plasmar en sus lienzos e ideas el paisaje topográfico y regional de la época (Gibson, 1989: XI, xx).

16 "Friedrich Ratzel, el padre de la geografía humana, considerado también en las historias de la etnología como uno de los fundadores de dicha ciencia. De él se ha valorado, sobre todo, su papel decisivo en el triunfo de las ideas de difusión cultural, sus aportaciones al estudio de las migraciones, su insistencia en la unidad biológica fundamental del homo sapiens, y el haber realizado algo que no habían hecho antes otros autores, como Tylor, a saber: 'una descripción de los pueblos vivientes agrupados geográficamente" (Capel, 1989: 27).
} 
los distintos enfoques posibles en la geografía humana y lo hace en un artículo publicado para la Encyclopedia of Social Sciences en 1931 (idem).

En general, se pueden identificar por lo menos tres etapas en la historia de la geografía cultural: "el de la Escuela de Berkeley, el de la geografía humanista y el de la nueva geografía cultural” (López, 2003: 194). En una síntesis ajustada, la Escuela de Berkeley ${ }^{17}$ afirmaba que era indispensable estudiar la especificidad de las diferentes áreas culturales (Fernández, 2006: 225).$^{18}$ En cambio, las perspectivas de la geografía humanista basan sus supuestos en "los fundamentos de la fenomenología, el existencialismo y el idealismo, sin embargo, los estudios geográficos adoptan, en especial, el marco fenomenológico vinculado, como sostienen S. J. Taylor y R. Bogdan" (en Santarelli y Campos, 2002: 154). Finalmente, los principios rectores de la nueva geografía cultural serían la "crítica a los conceptos sauerianos de cultura y paisaje [y el énfasis en] las categorías de espacio y espacialidad a diferencia de la geografía cultural" (Contreras, 2006: 173); llegando inclusive a considerar "que la geografía debería preocuparse esencialmente de los problemas de la cultura" (Capel, 1989: 35). Parte de los cambios que sufrieron las corrientes de pensamiento en la geografía después de la década de los cincuenta se muestran en el cuadro 2.

Con la incorporación de la variable cultural se intenta abrir el debate sobre la complejidad de la región como unidad territorial, histórica, económica y política, y con ello generar nuevas lecturas no sólo del pasado y presente geográficos, sino además incursionar en los estudios de estrategias y proyección de realidades simuladas con la adición de las nuevas tecnologías a los análisis sociales. Así, se da paso a un diálogo incipiente entre las diferentes corrientes de la geografía. También se trata de ver esta disciplina como una variable inseparable de lo social y de las cuestiones regionales. Si apreciamos esta idea en sus orígenes, claramente se puede reconocer que la identidad de la geografía regional se ha mantenido unida a las metodologías divisionales y taxonómicas del territorio con parámetros medioambientales, políticos, grado de progreso, tipificación de la población, factores naturalistas, etc. Pero que en la actualidad el análisis geográfico, al nutrirse históricamente de categorías y cuerpos teóricos de distintas disciplinas, presenta una serie de perspectivas y desafíos que se

\footnotetext{
${ }^{17}$ Según lo que detalla López, "la Escuela de Berkeley ha sido atacada desde el punto de vista teórico, metodológico y político [...] que deriva del escepticismo que mostraba Sauer hacia la teoría en las ciencias sociales y naturales (Rowntree: 1989: 221). Metodológicamente se acercó más a la geología y a las ciencias de la tierra que a la historia y a las humanidades (Jackson, 1992: 15). El trabajo de campo consistía en la simple observación complementada con algo de investigación documental [...] y sus investigaciones han sido juzgadas como apolíticas (Price y Lewis, 1993: 4)" (López, 2003: 195).

${ }^{18}$ Uno de los legados de esta escuela es que ha contribuido con varias generaciones de geógrafos latinoamericanistas preocupados por el estudio de la geografía cultural, humana y regional de América Latina (Caviedes, 2005: 50).
} 


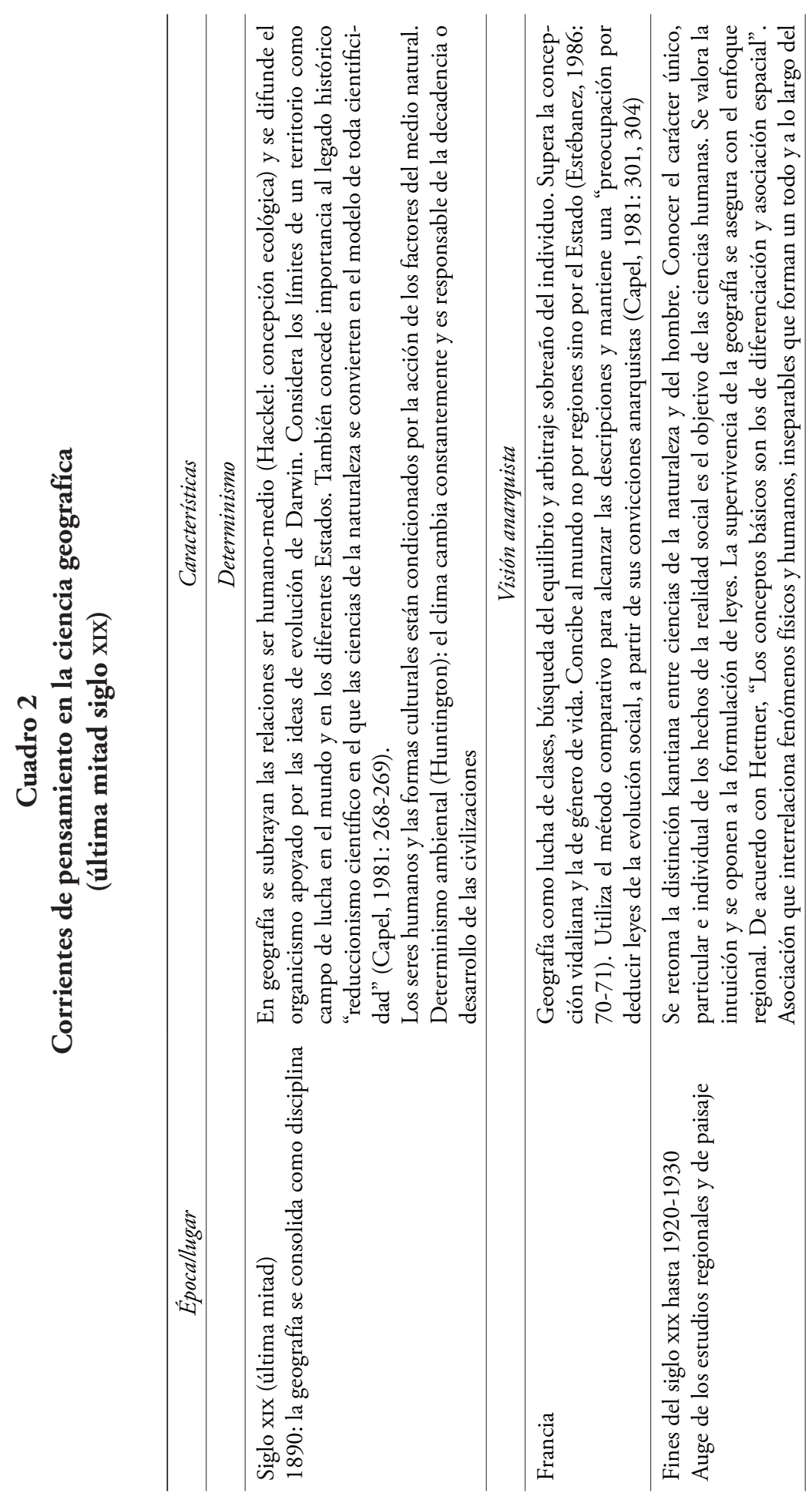




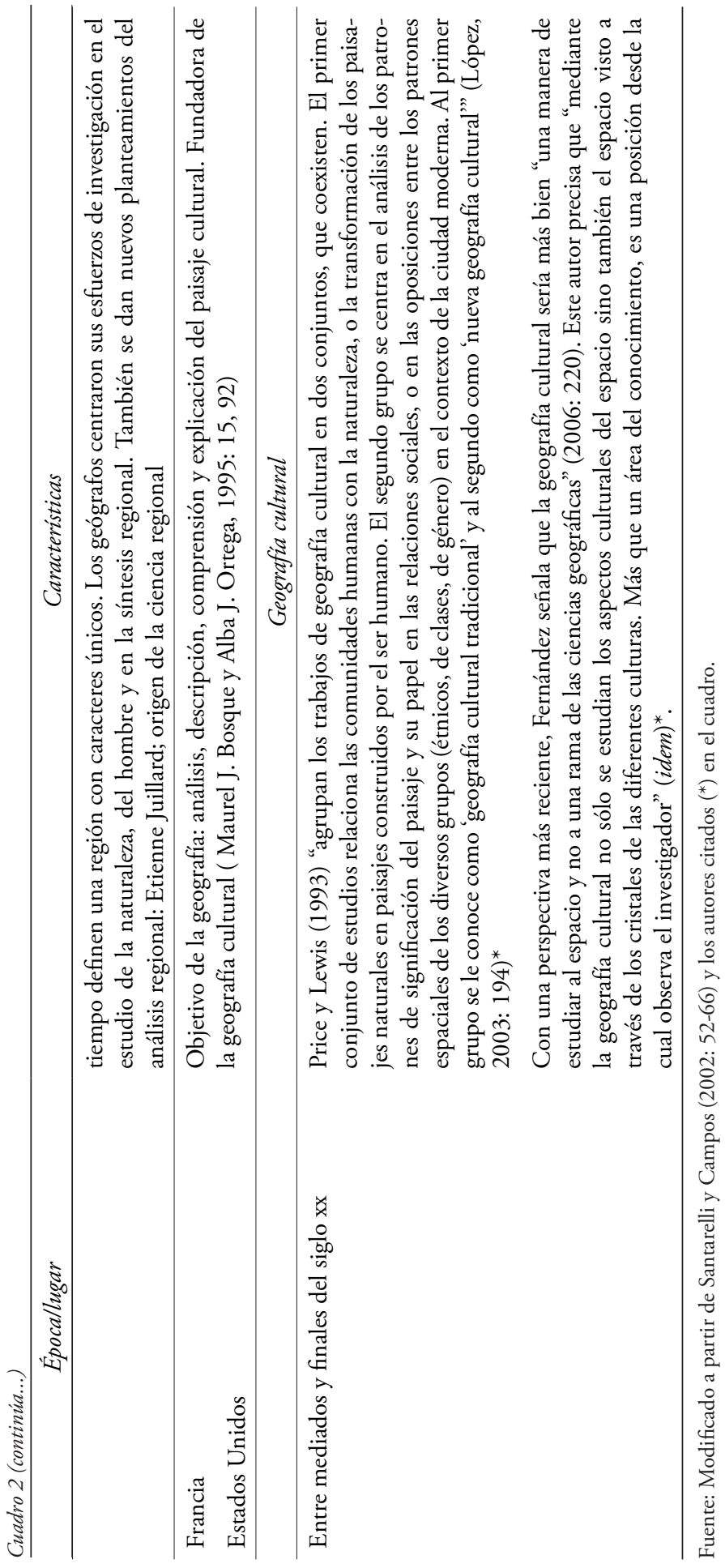


vuelven un imperativo en el análisis general del espacio. También se debe considerar que la parte cultural es ineludible del espacio en su totalidad. En el pasado como en el presente, la región ha sido sinónimo de seguridad para quienes quedan dentro de la muralla o frontera que delimita el espacio, en otro tiempo también ha significado la apropiación del espacio para fines individuales o colectivos, ostentación de riqueza o poder, estrategia de supervivencia o dominio; reconocimiento que ha sido aprovechado ventajosamente por individuos, colectivos, imperios, Estados, grupos de poder, etc., en detrimento del espacio y espacialidad de otros. La difícil labor es entender cómo las configuraciones regionales de hoy tienen una naturaleza que las vincula con su pasado y presente culturales.

Queda claro que, por un lado, la delimitación o posesión del espacio es algo inherente a la naturaleza social y cultural de individuos y colectivos. Pero por otro, la regionalización también ha sido una manera estratégica de organización, planeación y logística social dentro y fuera de los Estados nacionales. Esto se puede constatar en la propia historia de la humanidad, tanto en su etapa nómada como sedentaria. De hecho, el rompecabezas mundial tiene en su origen y presente la idea de región. Así han cobrado fuerza los tratados bilaterales, multilaterales, mundiales y muchas de las propuestas hechas por organismos internacionales preocupados por una distribución más equitativa de los ingresos. Sin embargo, también se tienen ejemplos donde el proceso de regionalización ha fracasado. Ante esto, una de las variables que aparecen en el juego es, evidentemente, la cuestión cultural. Pero no como un elemento abstracto, incomprensible o ajeno, sino como una variable que aparece antes o después de regionalizar un espacio. Se pone en cursivas pues en realidad la cultura está implícita en cualquier formación regional, sólo que quienes regionalizan llegan a subestimarla o marginarla por completo. Esto no debería ser así, pues en el fondo la perspectiva cultural es una manera de entender lo social como una expresión de modos distintos de vida, de pensar o percibir el mundo. En estos términos la variable cultural estaría en los eslabones económicos, políticos y sociales que se ligan inexorablemente a la idea de región (ver, inter alia, Agnew, 2000; Lagendijk, 2006; Massey, 1978; Paasi, 2002; Störper, 1997, en Pike, 2007: 1143, figura I). En otro orden de ideas, esto quiere decir que en las regiones hay un traslape de relaciones diferenciadas y diferenciales que dependen de la posición, dirección, sentido, identidad y acomodo que guardan los propios actores que las crean. La región también se puede concebir como una síntesis de procesos evocados por las conectividades, declives y rupturas de los movimientos sociales, cuyo reconocimiento deriva de la experiencia del hacer, de la significación y de la afección. De ahí que entender la idea de región nos remita a un reconocimiento eminentemente reticular, tanto en su 


\section{Figura I}

\section{Algunos elementos esenciales que conforman la idea de región}

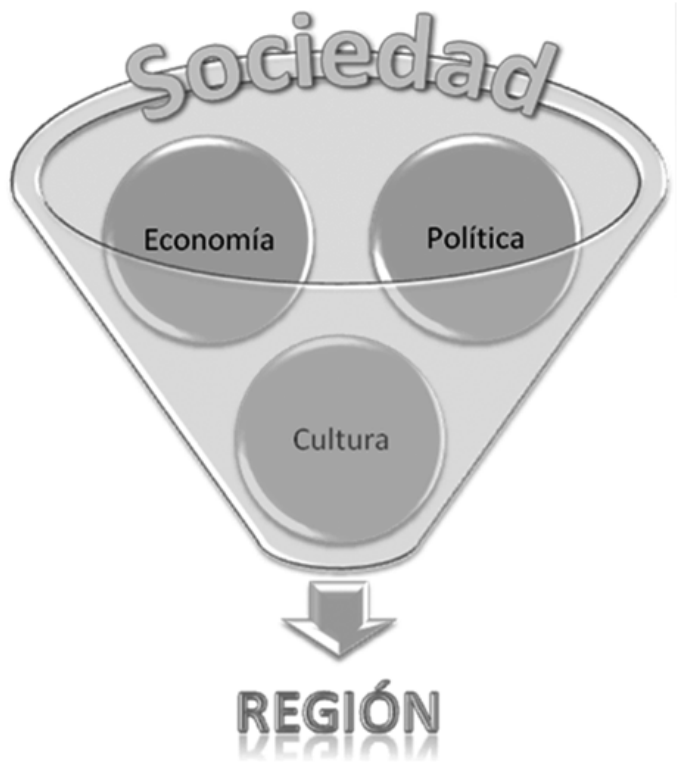

Fuente: Elaboración propia con base en Pike (2007: 1143).

génesis corológica como en su manifestación social, económica y cultural. Pues, como dice Pereda, "no hay clases culturales sin acciones que las produzcan" (2007: 211). Parafraseando esta idea se diría entonces que no hay regiones sin acciones que las produzcan.

Por los precedentes mencionados, el espacio regional sólo se puede entender como un tema que ha generado fértiles debates y que se ha convertido en objeto de distintas disciplinas. En estricto sentido, en el marco de la geografía regional, la región ha resultado ser un dispositivo de análisis y herramienta práctica que se construye sobre diferentes lógicas de exploración, estructuras de orden, circunscripción, perspectivas, necesidades, logísticas y jurisdicciones. Rasgos que no sólo han permanecido en el centro de polémica del pasado sino que además se enaltecen con los cambios sociales, económicos y geográficos del debate contemporáneo. De estos encuentros han derivado innumerables ensayos que estudian analítica y descriptivamente combinaciones o ramificaciones de los postulados regionales; donde las aproximaciones a los objetos de estudio suceden en forma interrelacionada y desde diferentes plataformas de lectura. Esta posición ha suscitado una serie de argumentaciones y posturas polémicas, al punto de llegar a cuestionar la propia existencia de la 
historia regional (Miño, 2002, en Taracena, 2008: 182). El punto aquí es empezar a vislumbrar los retos que vienen de frente, sobre todo cuando hay que desplazarse entre la teoría y la praxis de la idea de región.

\section{Perspectivas y desafíos de la geografía: un estado recursivo entre la teoría y la praxis}

En sentido amplio, las enmiendas ontológicas y las clasificatorias del espacio han generado debates controversiales, cuestionando inclusive los orígenes y perspectivas de la geografía regional. Cabe señalar que hay diferentes maneras de entender lo limítrofe que circunda al concepto de región. Sin embargo, no siempre fue así, ya que durante mucho tiempo "la geografía regional no se interesó por el espacio más que como un contenedor, con existencia absoluta e independiente de los fenómenos contenidos en él, o como superficie terrestre modificada por el hombre, y en este caso, espacio, región y territorio eran objetos idénticos de descripción y análisis geográfico" (Delgado, 2003: 28). Los primeros análisis sobre lo regional se dieron en el marco de la modernidad, y en particular, en la modernidad industrial. Es entonces cuando se abren los debates sobre la homogeneidad del espacio, pero al mismo tiempo ocurre una pulverización de esta disciplina en un sinnúmero de geografías (la física, la humana, la industrial, la rural, la urbana), fragmentando así las visión que se tenía del espacio (Moreira, 2006: 14-45, en Ramírez, 2009: 112). Esto trajo consigo dos consecuencias inmediatas. Por un lado, se trababa de explorar la ontología del espacio como un ámbito homogéneo y, en el otro extremo, estaba el resquebrajamiento de un cambio que anunciaba una serie de heterogeneidades al interior de los territorios. La discusión comenzó sin principios reconciliadores que dieran cabida a otras formas distintas de ver la geografía. El potencial explicativo de ambas posturas se neutralizó cuando se retomó la discusión con la intención de incorporar nuevas ideas, conceptos, epistemologías, teorías y metodologías al renovado debate. Esto sucedió en el intersticio discursivo de la modernidad y la posmodernidad.

Es en "la última mitad del siglo xx cuando -como consecuencia de las transformaciones ocurridas en tecnología, en la sociedad e ideologíasse producen innumerables debates y un continuo replanteo sobre las cuestiones epistemológicas, metodológicas y ontológicas en las ciencias" (Santarelli y Campos, 2002: 39). Sin escape alguno, la geografía sufre de nuevo algunas debacles en sus objetos de estudio y en los modos de abordar su problemática. En este marco, se empezó a hablar de forma más ferviente del problema de la interdisciplinaridad, homogeneidad-heterogeneidad, la visión particular-general, cualitativo-cuantitativo, lo local- 
global y otros aspectos relacionados con la problemática del espacio, sobre todo aquélla que tenía que ver con el espacio regional. De igual manera, se analizan de forma más profunda los cambios en las delimitaciones tradicionales del espacio basadas en el paisaje, relaciones espaciales, variables homogéneas, elementos predefinidos, actividades y funciones dominantes, etc. Máxime con los cambios que proclamaba el siglo xx en sus aspectos económicos, políticos y tecnológicos. En este sentido, la geografía, y en particular la geografía regional, aventajó en amplias proporciones la discusión.

Sin parangón, el siglo xx es el referente más cercano que da cuenta de la mayor celeridad en los procesos de información, cognitivos y de comunicación a escala mundial. Es en este marco en el que se suscita una serie de consideraciones críticas sobre la temporalidad inherente a los encuentros relacionales; la noción de distancia en términos de conectividad más que de cercanía o lejanía geográfica; la velocidad de los flujos y de las plataformas en que se desarrollan; las transformaciones cualitativas del sustrato de la simultaneidad en las relaciones. Se trata, entonces, de encontrar los puntos nodales del entretejido de ideas que ciñen al espacio y al territorio como la materia prima de los estudios sociales y territoriales, particularmente aquéllos relacionados con los cambios actuales incitados por la tecnología y sus derivados. El desplazamiento e interacción de los diversos campos científicos ha abierto diferentes rutas de navegación que trastocan la percepción y reconocimiento de identidades, categorías y fundamentos, las cuales se desempeñan con nuevas apreciaciones y cualidades.

Actualmente, los estudios regionales conciben a la región como el ámbito medular de referencia para abordar los cambios suscitados en el territorio. Cada vez hay un mayor interés por entender los rasgos distintivos internos de aquellos espacios que son homogeneizados a partir de referentes administrativos, económicos, geográficos o tecnológicos. Además hay un interés creciente por los tipos de interacciones, configuraciones y vínculos que se establecen a partir de una definición y difuminación permanente de actores, intermediarios y agentes. De este modo, la lectura del espacio ya no sólo se da como un elemento cartesiano subyacente, sino como verdadero constructo y cuerpo de investigación. Por tanto, el análisis de la situación de los procesos, transiciones y configuraciones relacionales aparece como la tríada que introduce los primeros cambios en la apreciación de las transformaciones espaciales. Es entonces cuando el territorio surge como el punto de contacto entre los discursos, percepciones, lenguajes, trayectorias, rutinas, representaciones y las vivencias, acontecimientos o estados relacionales de diferentes entidades que accionan lo social. 
Otra ruptura en las discusiones aparece cuando, en la década de los ochenta, se refuerza el binomio computadora-Internet y, con ello, el reconocimiento del ciberespacio como ámbito de cambios diferenciales en el contacto humano. Así, con la introducción de la Internet y la computadora se logró una verdadera efervescencia de derivados tecnológicos innovadores y periféricos, cuyo efecto sobrevino exponencialmente de los cambios en el habitar, trabajar y convivir diario. Este acontecimiento ha dejado su impronta en los estudios territoriales, tanto en sus objetos como en sus dispositivos de análisis. Con la incorporación de las nuevas tecnologías se abren modos alternativos en la investigación contemporánea de los espacios regionales y, por ende, maneras distintas de mirar el espacio social. Para este cometido se dispone de herramientas de software estadístico, sistemas de información geográfica, manejo de numeralias en versión digital, acceso a mapas por vía satélite, etcétera.

Por tanto, es posible demostrar que el análisis del espacio geográfico se puede abordar a partir de múltiples lecturas y con diferentes herramientas de análisis. Pero lo fundamental es que ante este abanico de posibilidades se enfatice el aspecto relacional que define los objetos, agentes, actores o unidades geográficas. Sin embargo, hablar de las estructuras espaciales, la dinámica de actores, la representación de la distancia y el tiempo, es también sumergirse en la idea de que el espacio se moldea y se transforma continuamente. En este sentido, aparecen distintos análisis sobre los flujos, la complejidad y las formas materiales que se presentan en el territorio. De igual modo, ahora la conectividad, accesibilidad y velocidad de contacto entre los actores sociales genera diferentes propuestas de abordaje metodológico y conceptual en las investigaciones geográficas contemporáneas. Ciertamente, esto tiene que ver con la organización, contacto y ejercicio de prácticas a diferentes escalas del territorio. Se habla entonces de explorar aquellas líneas de investigación que reconozcan los vínculos, encuentros y desplazamientos que se dan entre lugares, personas y momentos de distinta naturaleza.

En detalle, también se da un fuerte debate para tratar de dar mayor énfasis a los aspectos sociales y humanos sobre los aspectos físicos. Se apela además por la reconciliación entre la geografía física y humana y por compartir objetos, teorías, lenguajes y metodologías. Del mismo modo, surge un interés creciente por "una nueva geografía" o "geografía regional reconstruida” (Thrift, 1983, en García, 2006: 39). Es en este marco que se estudia la genealogía y cuerpo disciplinar de la geografía. De acuerdo con lo que señala García, gran parte de este debate se ha desarrollado en dos sentidos: por un lado, el problema de la existencia, de la ontología del concepto regional y, por otro, la elaboración de 
taxonomías, ${ }^{19}$ tipologías o clasificaciones, cuestión eminentemente metodológica (García, 2006: 53). Si se atiende la primera referencia acerca de la ontología de región, ésta tiene que ver con la conformación simultánea o parcial del espacio como paisaje, territorio, región, espacio geométrico, un punto en una red más amplia de relaciones, un centro o una periferia en la división espacial del sistema político y económico (García, 2006: 54). En el aspecto metodológico relacionado con el ejercicio clasificatorio de las regiones, se ha llegado a hablar en general de espacios regionales en función del número de variables, escala u objetivos. Estas clasificaciones han derivado a su vez en otras más detalladas que se sitúan por su grado de regionalidad (regionness), nivel de integración o conectividad, configuración territorial, grado de urbanización, fronteras geográficas, actividades económicas, convenios políticos, etc. Algunos ejemplos de esto se aprecian en el cuadro 3.

Otra de las maneras más comunes de explorar una región es a partir de su delimitación conceptual o empírica, es decir su regionalización. En otros términos, esto significa que con la idea de región nace también el de regionalización; "procedimiento usado por urbanistas, antropólogos y geógrafos [...] es de carácter técnico y permite acotar los territorios que tienen características similares, y que varían dependiendo de los criterios utilizados para demarcar (delimitar) el espacio en cuestión" (Ramírez, 2003: 34). La regionalización ha sido muy utilizada en la toma de decisiones, sobre todo cuando tiene que ver con la planificación de recursos que impulsan o inhiben la dinámica socioeconómica de un espacio determinado. El proceso de dividir o marcar los bordes del espacio ha sido recurrente a partir de estrategias regionalizantes. Éstas se han convertido en un instrumento de análisis, pero al mismo tiempo han sido un dispositivo normativo institucionalizado. Con la regionalización se ha tratado de inventariar, controlar y delimitar los recursos de un espacio. En este marco, uno de los ejercicios más socorridos es circunscribir una región a partir de sus límites geográficos. En tal caso, se tendrían que considerar por lo menos cuatro enfoques: 1) el corológico, ${ }^{20}$ 2) la perspectiva de la

19 "Desde el punto de vista taxonómico, a su vez, se han avanzado tipologías de diverso orden basadas, bien en el número de variables manejadas (regiones de una, de dos o más variables, incluso regiones 'totales'); bien en el objetivo o elemento definitorio principal (regiones históricas, regiones políticas o administrativas, regiones naturales, regiones formales, regiones geográficas, regiones económicas homogéneas, regiones funcionales; regiones-sistema; regiones mentales o perceptivas, o regiones plan, regiones problema, regiones virtuales, regiones propaganda...); bien en la escala o nivel espacial de análisis (mundo, zonas, dominios, provincias, comarcas, localidades; o, dicho en otros términos, megarregiones, macrorregiones, mesorregiones, microrregiones...)” (García, 2006: 53).

${ }^{20}$ En específico, el enfoque corológico se difundió ampliamente en la ciencia a finales del siglo XIX y principios del xx, con esta perspectiva los investigadores buscaban la diferenciación regional y las particularidades y con ello establecer conceptos y teorías generales (Sagan, 2006: 7). 


\section{Cuadro 3 \\ Debate sobre la dimensión geográfica de la región}

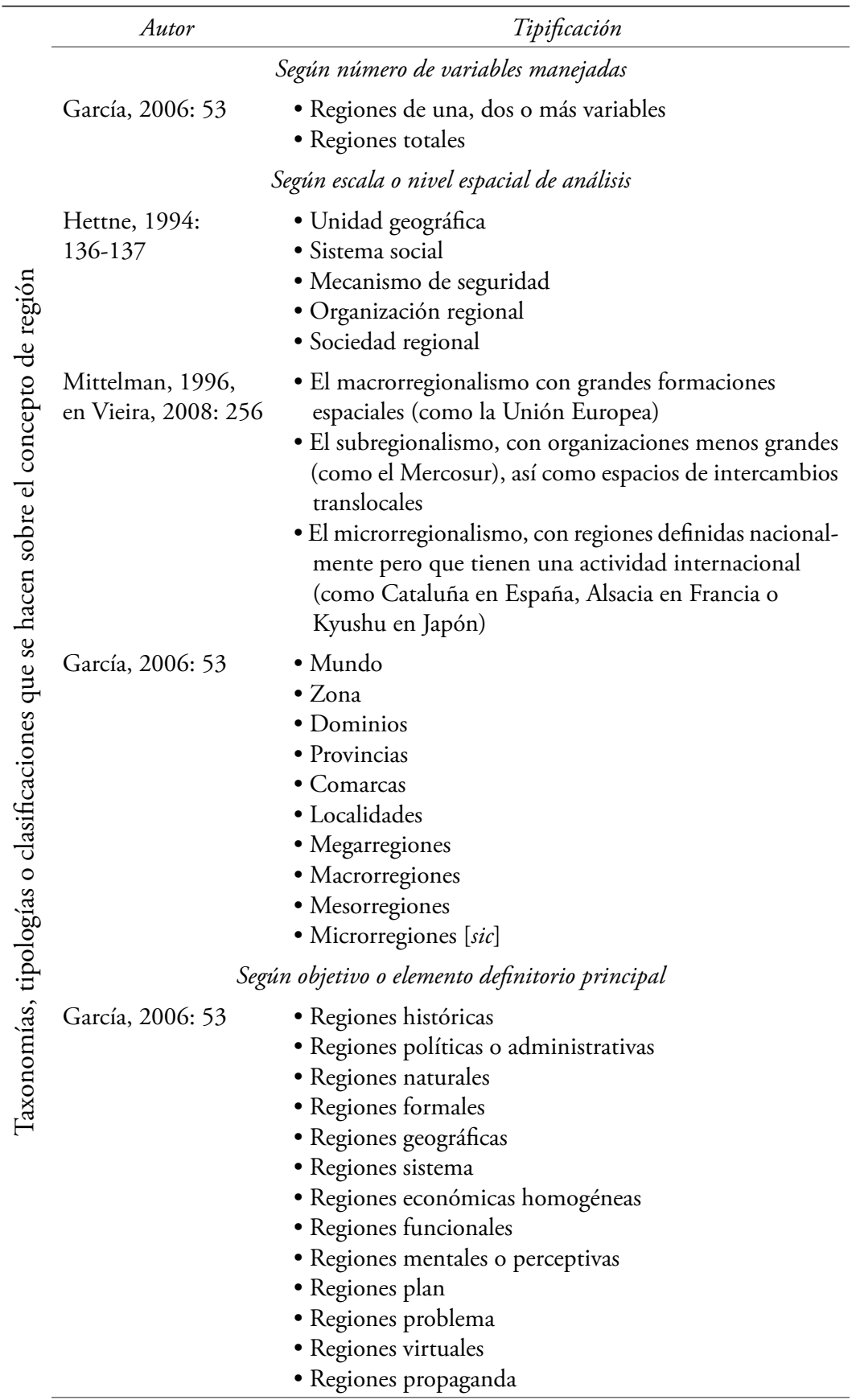




\begin{tabular}{cl}
\hline \multicolumn{1}{c}{ Autor } & \multicolumn{1}{c}{ Tipificación } \\
\hline Boisier, 1994: 185, & • "Pivotales" \\
en Vieira, 2008: 252 & • Asociativas \\
& • Virtuales \\
Delgadillo, 1990, en & - Por su pragmatismo político y/o funcionalista, aquí se \\
Carreto, 2000: 81-82 & ubican las regiones mediante criterios subjetivos respecto \\
& a la selección de fronteras y áreas regionales, ubicando \\
& en este grupo la región modal o funcional, la de rasgo \\
& simple, la de rasgos múltiples, las formales o uniformes, \\
& la de programa y la polarizada \\
& - Por las propuestas teóricas de carácter genérico, aquí se \\
& localizan las regiones que tratan de incidir en el contexto \\
& global de las acciones políticas, toman como marco de- \\
& terminante el contexto económico de la nación, que \\
& incluye las regiones: geográfica, económico-administra- \\
& tivas, histórico-económicas y socioeconómicas \\
\hline
\end{tabular}

Fuente: Elaboración propia con base en los autores citados.

ciencia regional, ${ }^{21}$ 3) el análisis de las estructuras sociales y espaciales ${ }^{22} y$, finalmente 4) la aproximación humanística ${ }^{23}$ (Sagan, 2006: 6, figura II). Así han surgido planes y programas operativos para diferenciar y, al mismo tiempo, uniformar procesos y agentes. Al final estos intentos se convierten en cartas de navegación con serias dificultades para llevarlas a cabo. Ya que con suma frecuencia, los ensayos para edificar un espacio se han dirigido sobre todo a reconocer propiedades homologables -conceptuales o empíricas- más que atender los procesos o configuraciones relacionales que puedan definirla como un espacio regional.

La regionalización en el mundo contemporáneo también se ha retomado como un ejercicio práctico para aminorar las tendencias negativas de la globalización, ya que se considera que gran parte de los asuntos públicos se pueden resolver de forma más eficiente en el ámbito regional.

${ }^{21}$ Los estudios regionales fueron dominados por la ciencia regional, una disciplina que combina los enfoques económico, geográfico y de planeación y se centra en el análisis teórico y cuantitativo de los aspectos de la economía regional. La ciencia regional, la cual fue prácticamente creada por un hombre, un economista estadounidense, Walter Isard, en los ańos cincuenta, básicamente se ocupaba de aspectos como el desarrollo de los modelos empíricos cuantitativos y el análisis teórico puro de los procesos de localización y de la economía regional (Sagan, 2006: 7).

22 Con esta perspectiva las regiones se forman y desarrollan como resultado de una interacción social-regional, la cual es al mismo tiempo una precondición y un resultado de las relaciones sociales entre individuos, grupos e instituciones ocurridas en un fragmento específico del espacio (Sagan, 2006: 10).

${ }^{23}$ Con este enfoque se aprecian sobre todo el sistema de creencias, valores y significados de una comunidad dada, que conforma las relaciones tanto institucionales como sociales. En otras palabras, la cultura tiene una influencia decisiva en la naturaleza de las instituciones que han sido formadas por medio de la iniciativa social y que adoptan el desarrollo de varios sistemas regionales (Sagan, 2006: 10). 


\section{Figura II \\ La región como una superestructura para los sistemas sociales y naturales}

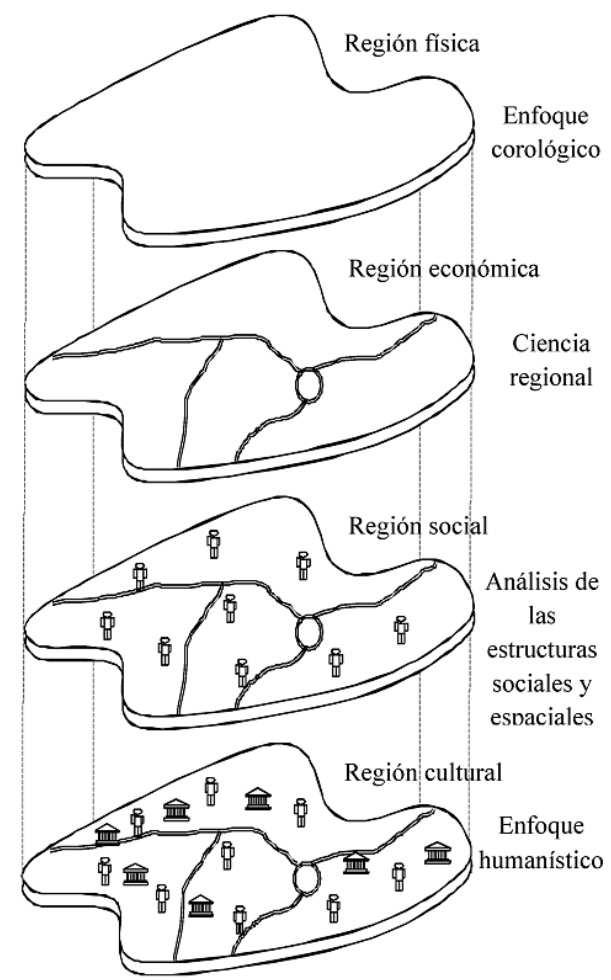

Fuente: Sagan (2006: 6).

Ante esto, es claro que la dimensión territorial está mediando de manera permanente la estrecha relación entre la región y el desarrollo de las actividades económicas y sociales. De hecho, el concepto de región se ha ido nutriendo de manera complementaria del cuerpo teórico de diferentes plataformas de la ciencia, lo que le ha valido una permanente renovación en el campo de los análisis territoriales. Por tanto, habría que señalar que la región siempre ha permanecido ligada tanto a los procesos como a los hechos que moldean los cambios sociales. De otro modo Sagan también lo reconoce cuando dice que

para presentar y evaluar la situación contemporánea de los estudios regionales, deberíamos analizar su dependencia de un amplio contexto socioeconómico y también su carácter evolutivo. Un intento de presentar la evolución en la definición y descripción de las regiones apunta a los vínculos lógicos y la sucesión entre los conceptos analíticos subsecuentes de la región, que pueden ser vistos como 
una prueba de continuidad y desarrollo evolutivo de ideas y conceptos concernientes a la región más que contradicciones revolucionarias en sus etapas individuales (Sagan, 2006: 5).

Particularmente, "los enfoques del nuevo regionalismo se hacen eco de la imposibilidad de aprehender desde una sola teoría la multiplicidad de los regionalismos contemporáneos, y amplían el campo de estudio de los procesos de regionalización y del regionalismo al cuestionar los marcos tradicionales de las disciplinas académicas establecidas y explorar nuevos campos interdisciplinarios (Söderbaum y Shaw, 2003, en Cabezas, 2007: 232). Este reconocimiento lleva a una relectura de los marcos teóricos y conceptuales vigentes, pues en sentido estricto hay una recomposición incesante de las estructuras sociales, que hoy difícilmente son alcanzadas por las explicaciones conceptuales y teóricas. En este sentido, uno de los desafíos es poder acceder a la comprensión de estos nuevos referentes del análisis territorial. Además de que habría que reconocer que la propia estructura del territorio, por medio de sus actores, intermediarios y contexto, es la que crea en forma inherente sus propias conectividades y sus propios desenlaces. Sin dejar de reconocer que lo social se transforma de manera continua en todas sus aristas, entradas, laberintos y salidas. Por tanto, se tendría que subrayar que una relectura de la región no se da sin tomar en cuenta las propias vicisitudes del cambio social. Una manifestación expresa de esta idea es que se ha intentado que la región evolucione a la par de los propios legados de los estudios territoriales y de otros campos de la ciencia.

De acuerdo con lo que señala Cabezas, "desde el nuevo regionalismo el proceso de surgimiento, transformación, creación y recreación de las regiones se entiende como contingente, constante y multidimensional. [Por tanto] al asumir la interacción de las dimensiones políticas, sociales y culturales con las variables económicas, el nuevo regionalismo permite abordar las relaciones económicas, ecológicas, étnicas, culturales y de género" (2007: 232). Éste es un signo diferente en el marco de los estudios territoriales, pues en esencia la concepción de región se precisa no de forma preestablecida, sino a partir de las propias diferencias limítrofes que cimentan la configuración misma del espacio en particular. Es decir, a partir de las relaciones y vínculos que los actores van edificando. En este contexto, se pone de manifiesto que cada movimiento, acción o proceso sería el incentivo permanente para nominar o definir en forma específica el perfil de la región en cuestión. En tales términos se hablaría de una definición dinámica del espacio, la cual cambiaría al unísono de las transformaciones que se suscitan en ella. Para ello habría que dar cabida a los modos diferentes de mirar el espacio, formas distintas de aprehenderlo o 
conceptuarlo. Esta intención encajaría en lo que también se ha llegado a denominar la nueva geografía, ${ }^{24}$ geografía radical, geografía humanista, cuyas visiones admiten "el empleo combinado de metodologías y técnicas cuantitativas, de la percepción radical y humanista que, en algunas circunstancias, coexisten en una gama conceptual heterogénea o, en otras, con manifestaciones claras de la línea adoptada" (Santarelli y Campos, 2002: 50). Por tanto, si se atiende el pensamiento geográfico en cuanto a las perspectivas de análisis, habría que reconocer por lo menos tres enfoques: 1) nueva geografía o geografía cuantitativa, 2) geografía de la percepción y 3) geografía humana (cuadro 4). Los detalles de estas corrientes se pueden apreciar a continuación.

Con tantos enfoques para abordar la problemática regional sería interesante lograr un esquema de análisis donde se entreveraran las distintas perspectivas y, con ello, construir los límites de un espacio regional; así como reconocer en este ejercicio la singularidad y densidad que se inscribe en los fenómenos sociales y físicos, pero también la posibilidad de reconciliarlos, después de la discordia con que han sido tratados. Sobre todo en la actualidad, cuando hay una necesidad imperativa de construir un tejido regional más integral e integrado que soporte los mecanismos complejos del poder económico, político y social frente a las agresiones persistentes al ambiente. Esta tarea no es fácil, pues detrás de una idea de región hay todo un espectro de referencias, tendencias y posicionamientos que entran en juego y que no son fáciles de evadir. Ante esto, se intenta poner de relieve la idea de que la región es una figura que se va moldeando según los cánones del tiempo, la conjugación de acciones individuales y colectivas y las experiencias de significación y apego que se dan en un determinado lugar. En este marco una región se da por la experiencia del hacer, de la significación y afección con el medio físico y social, más que por la experiencia de un decreto conceptual, ordenador o normativo en cualquiera de sus formas. Es cierto que los marcos institucionales son necesarios para definir los linderos de un espacio regional, pero su validación y reconocimiento responde, sobre todo, a una delimitación que se apuntala en los procesos de interacción social y de interacción con el medio físico. En tal caso, no se puede concebir lo regional sin apreciar en todo momento la colisión transformativa del espacio y de los distintos modos en que ha sido abordada y concebida. Esto no es una tarea de

${ }^{24}$ La búsqueda por la novedad no es reciente ni permanente. "Los hombres del Renacimiento habían sentido ya esta exigencia, primero al conocer la Geografía de Ptolomeo, y más tarde al emprender la tarea de rectificarla introduciendo en ella las tierras nuevamente descubiertas. Las relaciones de viajes y descubrimientos obligaron a corregir la obra del geógrafo alejandrino, y los atlas de Ortelio, Mercator, Janson y Blaew, entre otros, ayudaron a establecer y difundir una nueva imagen del planeta, contribuyendo con ello al desarrollo de un geografía verdaderamente nueva" (De Aguirre, 1981: 10). 


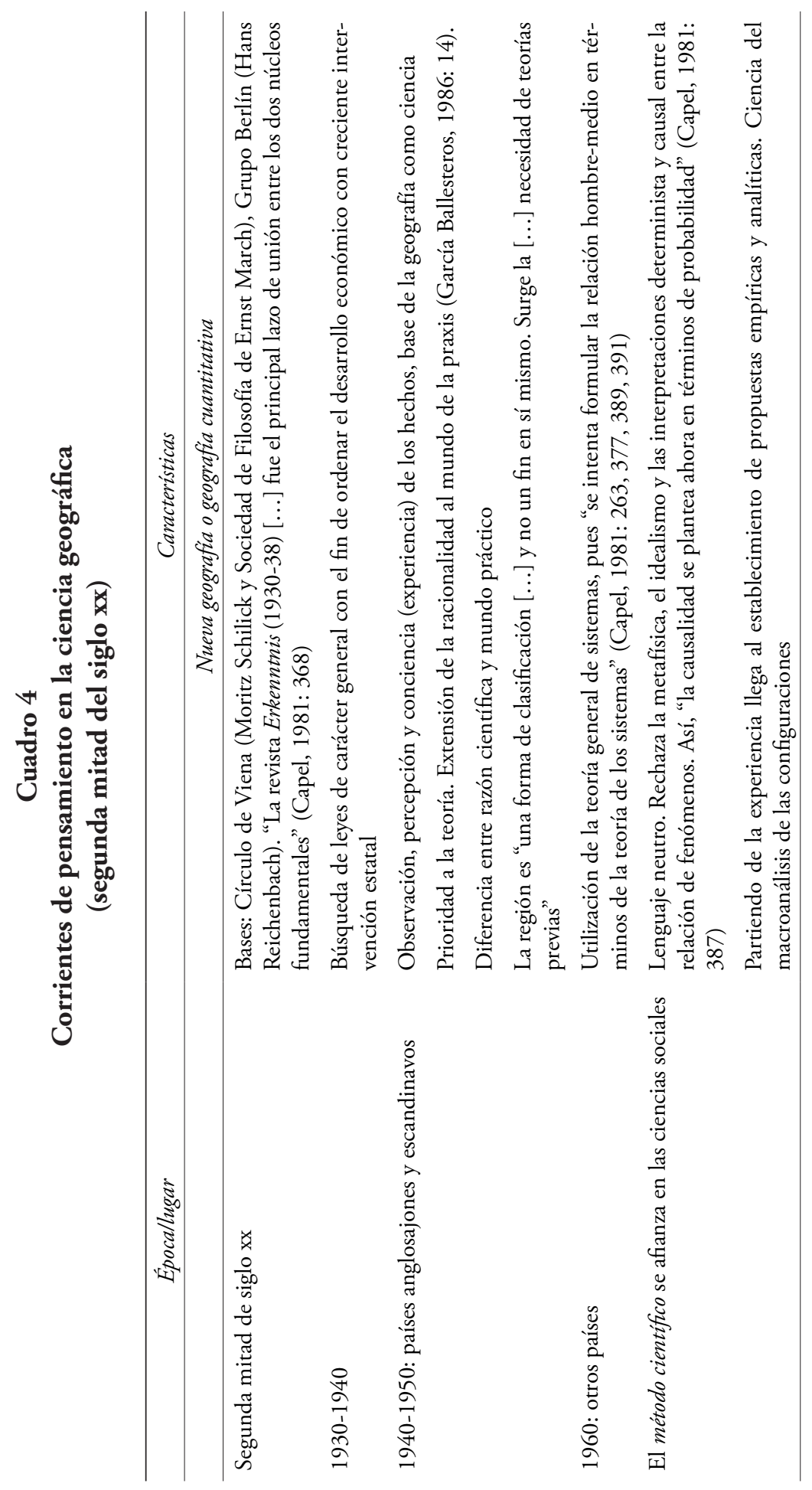




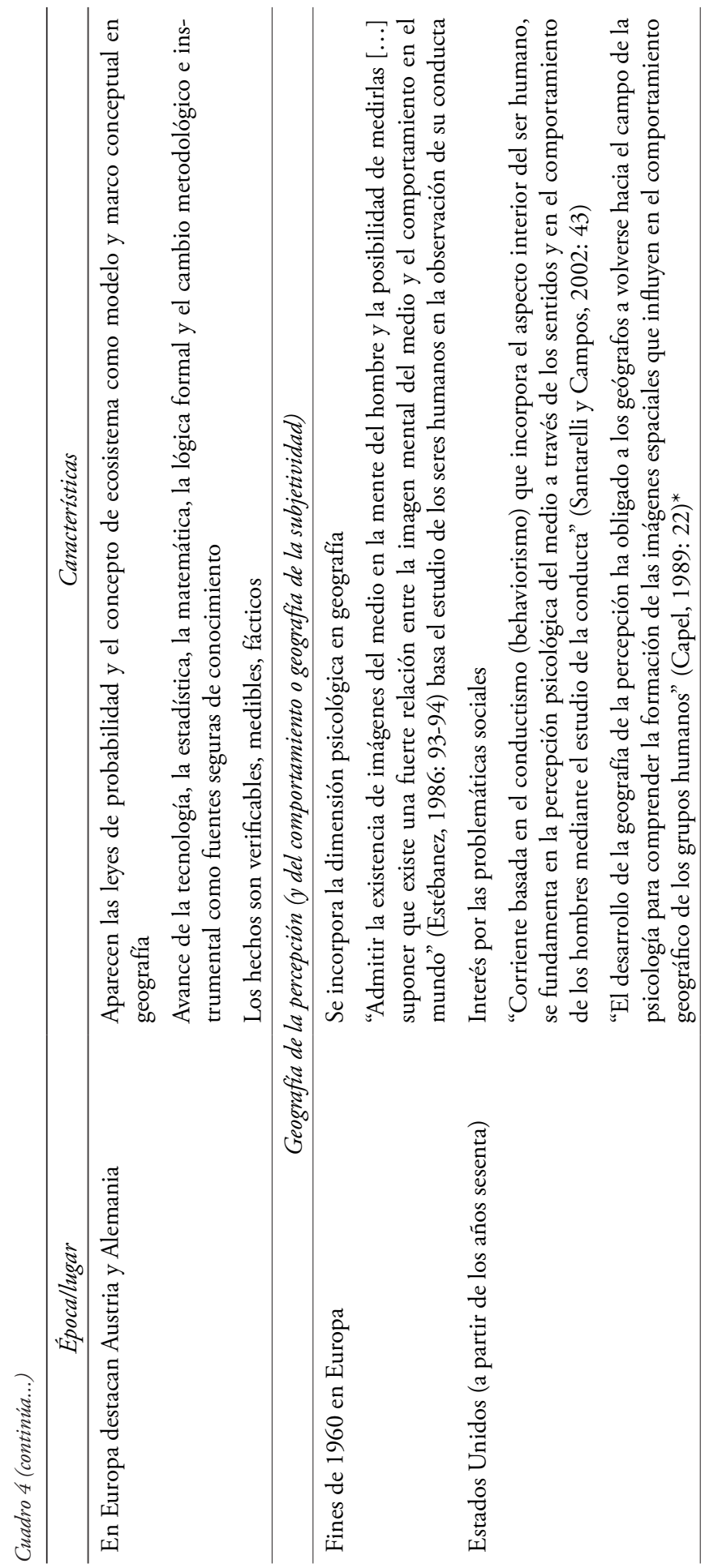




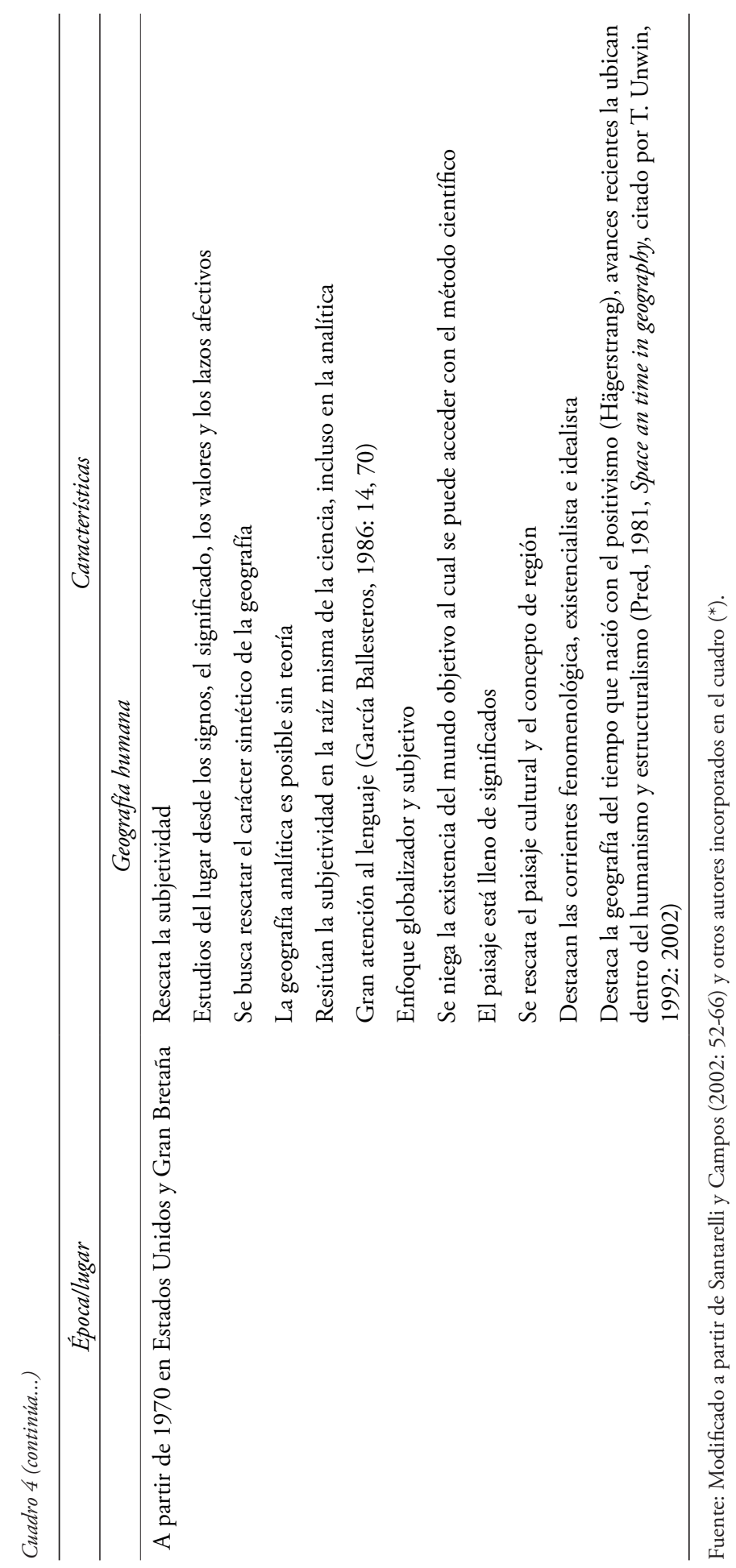


segundo orden, pues en muchos casos, al crear definiciones, categorías o delimitaciones regionales también se juega con la posibilidad de instaurar una forma modeladora del espacio social.

Por otro lado, en el mundo contemporáneo los procesos de regionalización han logrado un papel destacado en la política económica mundial; incidiendo de esta manera en los procesos socioeconómicos de distintos territorios, independientemente de su ubicación o escala geográfica. Así han nacido conglomerados territoriales de diferente tamańo que se asocian con fines estratégicos, económicos o políticos. De modo que hoy a la región se le puede apreciar a partir de por lo menos dos puntos de vista: 1) como una unidad territorial menor al Estado nacional, por ejemplo, la configuración individual o agregada que resulta de provincias, comunidades, municipios, Estados y 2) como una unidad mayor al Estado nacional, por ejemplo, la región del Tratado de Libre Comercio de América del Norte (TLCAN), Mercado Común del Sur (Mercosur), Unión Europea, Región Asia-Pacífico, etc. Sin embargo, la referencia con más adeptos en el ámbito académico ${ }^{25}$ y entre quienes toman las decisiones ha sido la primera, sobre todo para trabajos de corte empírico y como objeto de discurso teórico y práctico.

Así, en la actualidad se reconoce que las unidades territoriales que circunscriben el análisis geográfico regional invitan a explorar vías conceptuales y metodológicas alternas. En este contexto, hay una idea central que advierte sobre las formas y estructuras interactivas que transforman el territorio; las cuales habría que reconocer a partir de trayectorias, momentos y configuraciones espaciales que pueden verse desde una óptica distinta de estudio en la geografía regional. Así, la región aparece como un dispositivo transformado por una serie de cambios en las perspectivas y dinámicas espaciales y territoriales. Valdría la pena incursionar en las zonas de transición y fisura que circunscriben los linderos de la discusión sobre la espacialidad y territorialidad de los fenómenos sociales. Hoy, los procesos de integración mundial y los desafíos de los cambios globales han reavivado la vieja discusión sobre la problemática regional. Sobre todo cuando se ha podido reconocer que cualquier unidad territorial macro está conformada por unidades más pequeñas, que a su vez son afectadas por los cambios dados en otras latitudes. Sin embargo, en esto también habría que reconocer que pese a la inadvertida presencia en el mapamundi de algunas de estas unidades, todas contribuyen de un modo u otro en la geografía diferencial presente entre las economías líderes y las emergentes.

\footnotetext{
${ }^{25}$ Muestra de ello es la referencia del economista chileno Sergio Boisier (1996: 56), quien reafirma la idea de que "el concepto de región es más propio de una escala geográfica subnacional que de otras mayores".
} 


\section{Consideraciones finales}

Históricamente, la región se ha plegado a la idea de unidad, homogeneidad, igualdad y otros sinónimos derivativos. Esto trascendió sobre todo en el discurso modernista, ${ }^{26}$ donde no se veían las diferencias internas o las comparativas entre unas regiones y otras. Sin embargo, con la posmodernidad se readecuan las escalas de análisis de los territorios, favoreciendo la importancia de lo micro y negando, en ocasiones, la escala macro como una parte importante de la dinámica propia que las regiones adoptan; dando énfasis a las diferencias, deconstruyendo la homogeneidad que prevaleció en los tiempos pasados de la modernidad (Ramírez, 2003: 37). De hecho, aún en el presente la idea de homogeneidad permea muchas de las regiones institucionalizadas, con la discrepancia que hoy se empiezan a reconocer las diferencias que unen u orientan campos de vinculación heterogéneos. Hasta ahora, aunque parezca contradictorio, la variedad se entreteje de tal modo que puede lograr la configuración de regiones fortalecidas precisamente en una diferencia compartida. La región aparece así como un referente creador de subordinaciones y empoderamientos que atraviesa las escalas geográficas de acción. Su delimitación en primera instancia no es morfológica sino relacional. Con esta condición, una regionalización redefiniría y orientaría sus parámetros al principio de recreación permanente del espacio. La homogeneidad, como rasgo común en la idea de región, guió las prácticas que delimitaron territorios en el pasado, sin embargo, hoy se reconoce que las unidades territoriales que circunscriben el análisis geográfico regional incitan a explorar vías conceptuales y metodológicas alternas. En este contexto, hay una idea central que advierte sobre las formas y estructuras interactivas que transforman el territorio; las cuales habría que reconocer a partir de trayectorias, momentos y configuraciones espaciales que pueden mirarse desde una óptica distinta de estudio en la geografía regional. La región aparece así como un dispositivo transformado por una serie de cambios en las perspectivas y dinámicas espaciales y territoriales. Valdría la pena incursionar en las zonas de transición y fisura que circunscriben los linderos de la discusión sobre la espacialidad y territorialidad de los fenómenos sociales. De igual modo, habría que detenerse en los cambios y replanteamientos conceptuales que definen actualmente las fisuras de la idea de región. Sobre todo cuando en las regiones existen empalmes de otras regiones. La intención

\footnotetext{
${ }^{26} \mathrm{La}$ importancia de la región en la modernidad no fue asegurada sino hasta que se introdujo como un instrumento de organización de la realidad del mundo, es decir, a la economía con el fin de buscar nuevamente la integración que el proceso capitalista no logró; en otras palabras, cuando se transformó en la unidad territorial de instauración del proceso de desarrollo económico durante la posguerra (Ramírez, 2003: 34).
} 
es, entonces, un imperativo por reconocer cuáles son esas regiones, sus rasgos y qué tipo de configuración geográfica o relacional las define.

Tradicionalmente, el análisis de la región ha sido objeto de numerosas exploraciones. En los primeros acercamientos modernistas prevaleció la idea de homogeneidad, luego, desde la perspectiva de la posmodernidad se marcó la ruptura para reconocer la diferencia en la homogeneización. Sin embargo, en la actualidad los estudios regionales aprecian la región como el ámbito medular de referencia para abordar los cambios suscitados en el territorio. Ahora en las regiones hay un traslape de relaciones diferenciadas y diferenciales que dependen de la posición, dirección, sentido, identidad y acomodo que guardan los propios actores que las crean. Por estas razones, hay un mayor interés por entender los rasgos distintivos de los espacios homogeneizados, pero reconociendo de antemano que en su interior hay una serie de referentes administrativos, económicos, geográficos o tecnológicos que aun cuando son factores diferenciados, hay mecanismos relacionales que los unen. De igual modo se presenta una preocupación creciente por los tipos de interacciones, configuraciones y vínculos que se establecen a partir de la definición y difuminación permanente de actores, intermediarios y agentes. Sin duda, estas demandas se están incorporando en la definición de las perspectivas de análisis que cimentan los estudios territoriales contemporáneos.

De modo que la lectura del espacio ya no sólo interesa como un elemento cartesiano subyacente, sino como verdadero constructo y cuerpo de investigación. El análisis de la situación de los procesos, transiciones y configuraciones relacionales aparecen, entonces, como la tríada que introduce los primeros cambios en la apreciación de los procesos espaciales contemporáneos. Evidentemente, es entonces cuando el territorio surge como el punto de contacto entre los discursos, percepciones, lenguajes, trayectorias, rutinas, representaciones y las vivencias, acontecimientos o estados relacionales de diferentes entidades que accionan lo social. Como se vio a lo largo de este trabajo, las teorías han abundado en el estudio del territorio, aunque ciertamente la experiencia también nos demuestra que en muchos casos se han oprimido los métodos de construcción del objeto, sus interacciones y mutaciones desde la propia realidad donde se desarrollan.

Con la introducción de tecnologías de la información y cognitivas, como herramientas opcionales en los estudios contemporáneos, se han abierto otras posibilidades para explorar las configuraciones regionales en todas sus latitudes. En este caso, las escalas y la acción se articulan por procesos de acción mutable, donde la relación espacio-tiempo aparece redefiniendo las propias formas de relación. Éste es un reconocimiento que no pueden eludir los estudios contemporáneos. En otras palabras, 
habría que reparar en los rasgos particulares de referencia. En tal caso, se tendría que reconocer la transformación espacio-temporal particular de cada unidad territorial, y retomar el término región sólo cuando se justifique metodológica y conceptualmente. No se vale usar la categoría regional cuando el ámbito de análisis no cubre los mínimos justificantes teóricos o empíricos.

Ahora es frecuente encontrar una serie intermitente de trabajos que abordan los microcasos omitiendo los procesos, contextos y ámbitos espacio-temporales en que se insertan. Parecería que ya no son necesarios los métodos, pues ahora lo que abunda son los estudios de caso descriptivos, que se detienen poco en el ámbito teórico y menos aún en los procesos de construcción de los fenómenos territoriales. Se han omitido de manera permanente las dimensiones interrelacionadas a las que dan lugar los procesos tecnológicos, inminentemente relacionados con los procesos de cambio en el territorio. Otro error frecuente es seguir considerando a la región como un ámbito de referencia meramente homogéneo, cuando al interior existen diferencias permanentes de reconocimiento, que a final de cuentas dan el sentido de identidad que se busca en un proceso de regionalización.

Es frecuente encontrar que las formas emergentes de relación en un ámbito regional se articulan con las existentes o preexistentes. De ahí que se tendría que tender un puente entre el pasado y el presente de una región, pues ambas perspectivas coadyuvan en la comprensión de las trasformaciones y situaciones que avivan una región. Otra manera de expresar esta idea es que "el contexto adquiere dinámica y movimiento, en la medida en que cada momento de una región conjunta diversos acontecimientos que definen las características que la hacen individual sobre otras regiones" (Ramírez, 2003: 44). En específico, "en el análisis del territorio, el contexto está dado por las condiciones y características del momento, en donde se insertan los hechos, las cosas, los discursos, los eventos y los procesos" (idem). Ante esto, el reto del saber geográfico es poder consolidarse como una herramienta de análisis que conciba la naturaleza, densidad y estructura relacional de unidades territoriales llamadas regiones. En especial cuando hay una necesidad apremiante de encontrar mecanismos de regionalización efectivos y apegados a los estados diferenciales en que se desarrolla lo social. Sobre todo en aquellas latitudes donde la regionalización ha sido un quehacer de segundo orden y con altos costos sociales.

Pero, sin lugar a dudas, la exploración o develamiento de lo social remite de manera inmediata a problematizaciones sobre las múltiples estructuras materiales, simbólicas e intangibles dadas en el territorio y el espacio. Los componentes tangibles o materiales son aquellos medios o 
vehículos estabilizantes que permiten enlazar o reunir equipos, productos o personas a partir de soportes materiales de diferente índole. Las estructuras simbólicas, en su referencia más simple, tienen que ver con las expresiones abstractas que adoptan, comparten, apropian o individualizan determinados actores al entrar en un juego de correspondencias, referentes, identidades, distinciones, asignaciones y apegos. Para el caso de los componentes intangibles habría que definirlos como aquellas manifestaciones no materiales provistas de atributos, convenciones, expresiones codificadas, protocolos, visiones, creencias, conocimientos o ideas particulares que se desplazan, arraigan o circulan en la praxis cotidiana de la interacción. Lo interesante aquí es que las trayectorias entre el punto inicial y final que circunscribe una región se desdoblan, hilvanan, interconectan y se rehacen continuamente. Sin dejar de reconocer que hay un evidente rebasamiento de los cambios actuales sobre lo conceptualizado, lo dicho y lo escrito hasta ahora. El reto, entonces, es poder asomarse entre aquellos resquicios de lo social y ordenar algunas ideas sobre lo que se alcanza a vislumbrar desde nuestro ángulo y a partir de nuestra plataforma de apreciación. La travesía promete ser fecunda a pesar del caudal de momentos que circundan el laberinto cambiante de lo social. Sin embargo, también hay que reconocer que todo intento de síntesis analítica es problemática, sobre todo cuando la efervescencia de los cambios nubla la dirección hacia la que intentamos dirigirnos.

Darles voz a los actores significa reconocerles en su expresión social y territorial particular. Esa voz, más que un mero dispositivo descriptivo o accesorio, es un elemento constitutivo de su propia reproducción social. Esto cobra sentido en el espacio del actuar cotidiano, pues es en éste donde se hilvanan las narraciones de quienes habitan y crean ese espacio. $\mathrm{Al}$ extrapolar esta idea, se puede decir que el espacio se convierte así en un mosaico de articulaciones variables donde se enuncian voces, discursos y ecos con distinta intensidad. Un ejercicio obligado es no dejar que el objeto de estudio se quede sin sujetos, es decir, sin voces y discursos, y en contrapeso, sin intérpretes ni traductores. En definitiva, "si el lenguaje es constitutivo de realidades y constituye un medio para actuar sobre el mundo, incluidos nuestros semejantes, también cabe esperar que incida por lo tanto en la conformación y el desarrollo de las relaciones sociales y de las prácticas sociales" (Ibáñez, 2006, en Íñiguez, 2006: 40-41). Este reconocimiento se percibió y adoptó para la tarea de tratar con los objetos y cuerpos teóricos que moldean el análisis social, en particular el análisis territorial. Un reconocimiento ineludible es que el ser social desarrolla el lenguaje, signos, significados, símbolos y discursos a partir de su relación con el espacio o territorio. En este sentido, territorio y sociedad es un 
binomio inseparable, pues ambos comparten el mismo espacio relacional y discursivo que crea lo social.

Otro aspecto certero es que el discurso de lo social se nutre a su vez de otros discursos. Al punto de formar una serie de hipervínculos entreverados por las estructuras argumentativas de distintas disciplinas. En este sentido ningún conocimiento, postulado o teoría aparecen de la nada, siempre tienen algún precedente o consecuente que los liga. Entre la efervescencia de los cambios surgen perspectivas que de forma continua generan un nuevo resquicio en el conocimiento, favorecidas precisamente por los avances o propuestas de otros espacios disciplinares. Estos encuentros y desencuentros coadyuvaron al fortalecimiento del avance en los estudios territoriales, en particular aquellos que tocan el tema de la región. Una consecuencia directa de los estudios contemporáneos es que se han promulgado filiaciones entre disciplinas heterogéneas, abriendo de este modo un campo mayor de posibilidades explicativas y metodológicas. Particularmente, la metodología es un ejercicio que condensa los abordajes teóricos, la renovación o desecho de certidumbres y lo fáctico de la naturaleza de los vínculos; para después dirigir la mirada a los intervalos explicativos entre lo local y lo global, lo singular y lo general, lo cualitativo y lo cuantitativo, la certidumbre y el azar, lo individual y lo colectivo.

No hay duda en pensar que aparecen estrategias de análisis controversiales, las cuales, sin embargo, enriquecen las miradas sobre la región y sus planteamientos teóricos y empíricos. Pero finalmente, ¿a qué remite la región, a una división territorial, una unidad geohistórica, una abstracción o un espacio relacional contingente que cambia en función de quien lo mira, lo crea o lo traduce? ¿Qué ha cambiado en la idea de región hoy respecto a sus precedentes? ¿Hay posibilidad de repensar el espacio y el territorio ante el planteamiento de la temporalidad y cambios en las configuraciones relacionales dadas por las tecnologías informacionales y cognitivas? Estas incógnitas se entrelazan para formar una síntesis de posibilidades donde se pueda repensar el papel de las entidades individuales y colectivas y los ámbitos donde interactúan. Es evidente que todo se crea y recrea permanentemente, lo interesante es poder describir esos cambios.

\section{Bibliografía}

Aguirre, Manuel de (1981), Indagación y reflexiones sobre la geografía con algunas noticias previas indispensables (1782), Universidad de Barcelona, Barcelona.

Birrell, Anne (2005), Mitos chinos, Akal, Madrid. 
Bocchetti, Nery Carla (2006), "Política y paisaje en la Ilíada", en III Jornadas Filológicas Noel Olaya Perdomo, Universidad Nacional de Colombia, Bogotá, pp. 121-137.

Boisier, Sergio (1996), Modernidad y territorio, CEPAL, Santiago de Chile.

Bosque, Maurel J. y Alba J. Ortega (1995), Comentario de textos geográficos (Historia y crítica del pensamiento geográfico), OikosTau, Barcelona.

Budge, Wallis E. A. (2007), El libro egipcio de los muertos. El papiro de Ani, Sirio, Málaga.

Bunster, Enrique (1977), Crónicas del Pacífico, Andrés Bello, Santiago de Chile.

Cabezas-González, Almudena (2007), "Mujeres centroamericanas frente al Plan Puebla-Panamá”, en Heriberto Cairo Carou, J. Preciado Coronado y A. Rocha Valencia (coords.), La construcción de una región. México y la geopolítica del Plan Puebla-Panamá, Universidad Complutense de Madrid-Instituto Universitario de Desarrollo y Cooperación (IUDC), Madrid, pp. 231-256.

Capel-Sáez, Horacio (1981), Filosofía y ciencia en la geografía contemporánea, Barcanova, Barcelona.

Capel-Sáez, Horacio (1989), Geografía humana y ciencias sociales. Una perspectiva histórica, Montesinos, Barcelona.

Carreto-Bernal, Fernando (2000), "Introducción a la geografía regional de México", en Alejandro Tonatiuh Romero Contreras (coord.), Espacio geográfico, Universidad Autónoma del Estado de México, México, pp. 77-84.

Caviedes, Cesar N. (2005), “Tradiciones geográficas modernas en los países de América del Sur", en Robert B. Kent, Vicent Ortells Chabrera y Javier Soriano Martí (eds.), Bridging cultural geographies: Europe and Latin America, Universitat Jaume I, Castelló de la Plana, pp. 35-58.

Contreras-Delgado, Camilo (2006), "Paisaje y poder político: la formación de representaciones sociales y la construcción de un puente en la 
ciudad de Monterrey", en Alicia Lindón, Miguel A. Aguilar y Daniel Hiernaux (coords.), Lugares e imaginarios en las metrópolis, Anthropos-Universidad Autónoma Metropolitana, Iztapalapa, Barcelona, pp. 171-186.

Croix, Nicollé de la (1779), Geografía moderna, D. Joachin Ibarra Impresor, Madrid.

Delgadillo Macías, Javier (2003), "Frontera México-Estados Unidos: integración regional de un territorio en transición", en Patricia Olivera (coord.), Espacio geográfico, epistemología y diversidad, Universidad Nacional Autónoma de México, México, pp. 35-61.

Delgado-Mahecha, Ovidio (2003), Debates sobre el espacio en la geografía contemporánea, Universidad Nacional de Colombia, Bogotá.

Dikshit-Ramesh, Dutta (2006), Geographical thought. A contextual History of Ideas, Prentice-Hall of India, Nueva Delhi.

Estébañez-Álvarez, José (1986), Tendencias y problemática actual de la geografía, Cincel, Madrid.

Fernández-Christlieb, Federico (2006), "Geografía cultural", en Daniel Hiernaux y Alicia Lindón (dirs.), Tratado de geografía humana, Anthropos-Universidad Autónoma Metropolitana, Iztapala, Barcelona, pp. 220-253.

Fernández-Cuesta, Gaspar (1988), "Hacia una estructura general del espacio", ERÍA, Revista de Geografía, 15, Universidad de Oviedo, Oviedo, pp. 27-39.

García Álvarez, Jacobo (2006), “Geografía regional”, en Daniel Hiernaux y Alicia Lindón (dirs.), Tratado de geografía humana, AnthroposUniversidad Autónoma Metropolitana, Iztapalapa, Barcelona, pp. 25-70.

García-Ballesteros, Aurora (coord.) (1986), Teoría y práctica de la geografía, Alhambra, Universidad, Madrid.

Gibson, Walter S. (1989), Mirror of the Earth: The World Landscape in Sixteenth-Century Flemish Painting, Princeton University Press, Princeton. 
Gil de Arriba, Carmen (2002), Ciudad e imagen. Un estudio geográfico sobre las representaciones sociales del espacio urbano de Santander, Universidad de Cantabria, Santander.

Gómez-Espelosín, Francisco Javier (2005), El descubrimiento del mundo. Geografía y viajeros en la antigua Grecia, Akal, Madrid.

Hale-Rigby, John (1993), La Europa del Renacimiento. 1480-1520, Siglo XXI, Madrid.

Hettne, Björn (1994), "The regional factor in formation of a new world order", en Yoshikazu Sakamoto (comp.), Global Transformation Challenges to the State System, Unite Nations University Press, Nueva York, pp. 134-166.

Hiernaux, Nicolas Daniel (1999), La geografía como metáfora de la libertad. Textos de Eliseo Reclus, Plaza y Valdés, México.

Holt-Jensen, Arild (2009), Geography, History and concepts: a student's guide, Sage, Londres.

Íñiguez, Lupicinio (2006), Análisis del discurso: manual para las ciencias sociales, Universitat Oberta de Catalunya, Barcelona.

López-Levi, Liliana (2003), "Geografía cultural y posmodernidad: nuevas realidades, nuevas metodologías", en Patricia E. Olivera (coord.), Espacio geográfico, epistemología y diversidad, Universidad Nacional Autónoma de México, México, pp. 193-208.

Lloyd, Geoffrey (2008), Las aspiraciones de la curiosidad. La comprensión del mundo en la Antigüedad: Grecia y China, Siglo XXI, Madrid.

Martín del Campo Amezcua, José, Fausto A. Chagollán Amaral, Ivonne B. Martín del Campo Becerra, Inocencio López Aguilar, Francisco González Reynoso, Laura Arcelia Romo Ríos y Rosalío Almaguer Ramírez (2006), Geografía, Umbral, México.

Mateos-Muñoz, Agustín (2003), Compendio de etimologías grecolatinas del español, Esfinge, México.

Mitchell, Donald (2000), Cultural geography. A critical introduction, Blackwell, Malden. 
Paniagua-Aguilar, David (2006), El panorama literario técnico-científico en Roma (siglos I-II d. C.) "Et docere et delectare", Universidad de Salamanca, Salamanca.

Pereda, Carlos (2007), "Mundo: un concepto tenso", en Guillermo Hurtado y Óscar Nudler (comps.), El mobiliario del mundo. Ensayos de ontología y metafísica, Universidad Nacional Autónoma de México, México, pp. 193-222.

Pérez-Largacha, Antonio (2006), Historia antigua de Egipto y del Próximo Oriente, Akal, Madrid.

Pike, Andy (2007), "Whither Regional Studies?", Regional Studies, 41 (9), Routledge, Londres, pp. 1143-1148.

Ramírez-Velázquez, Blanca Rebeca (2003), Modernidad, posmodernidad, globalización y territorio. Un recorrido por los campos de las teorías, Porrúa-Universidad Autónoma Metropolitana, Xochimilco, México.

Ramírez-Velázquez, Blanca Rebeca (2009), "Discursos de la geografía latinoamericana: teorías y métodos”, en G. Montoya y John Williams (eds.), Lecturas en teoría de la geografia, Universidad Nacional de Colombia, Bogotá, pp. 103-128.

Redondo-González, Ángela (2007), “Por las orillas de Gea y los labios de Océano: la Geografía”, en José Luis González Recio (ed.), Átomos, almas y estrellas. Estudios sobre la ciencia griega, Plaza y Valdés, México-Madrid, pp. 23-56.

Sagan, Iwona (2006), "Contemporary Regional Studies. Theory, Methodology and Practice", en Regional and Local Studies, Centre for European Regional and Local Studies-Warsaw University Regional Studies Association, Special Issue, Varsovia, pp. 5-19.

Santarelli de Serer, Silvia y Martha Campos (2002), Corrientes epistemológicas, metodología y prácticas en geografía. Propuestas de estudio en el espacio local, Universidad Nacional del Sur, Bahía Blanca.

Schlögel, Karl (2007), En el espacio leemos el tiempo. Sobre historia de la civilización y geopolítica, Siruela, Madrid. 
Taracena-Arriola, Arturo (2008), "Propuesta de definición histórica para región", en Estudios de historia moderna y contemporánea de México, 35, Universidad Nacional Autónoma de México, México, pp. 181-204.

Vieira-Posada, Édgar (2008), La formación de espacios regionales en la integración de América Latina, Pontificia Universidad Javeriana, Bogotá.

Recibido: 15 de enero de 2010. Aceptado: 30 de junio de 2010.

Ryszard Edward Rózga-Luter. Es doctor en ciencias económicas por la Universidad de Varsovia, Polonia. Actualmente es profesor-investigador del Departamento de Teoría y Análisis, División de Ciencias y Artes para el Diseño en la Universidad Autónoma Metropolitana, unidad Xochimilco y profesor en la Facultad de Planeación Urbana y Regional de la Universidad Autónoma del Estado de México. Es miembro del Sistema Nacional de Investigadores, nivel II. Su línea de investigación actual es desarrollo económico-regional. Entre sus últimas publicaciones destacan: "La dimensión local y regional de los procesos de innovación tecnológica", en G. Dutrenit (coord.), Sistemas regionales de innovación: un espacio para el desarrollo de las PYMES. El caso de la industria de maquinados industriales, Universidad Autónoma Metropolitana, Xochimilco-Textual, MéxicoMontevideo, pp. 20-32 (2009); "Estado actual de la investigación sobre las condiciones territoriales de innovación en México”, en Leonel Corona y José Molero (coords.), Los retos de la innovación en México y España. Política, universidad y empresa ante la sociedad del conocimiento, Akal, Madrid, pp. 213-222 (2009); en coautoría, Historia de la industrialización en el Estado de México (1930-1980), t. vi de Historia General del Estado de México, El Colegio Mexiquense-Gobierno del Estado de México, Toluca (2010); Técnicas para el análisis regional. Desarrollo y aplicaciones, Trillas, México (2009).

Celia Hernández-Diego. Es maestra en estudios urbanos y regionales por la Universidad Autónoma del Estado de México y doctorante en ciencias sociales por la Universidad Autónoma Metropolitana. Su línea de investigación es estudios territoriales sobre innovación tecnológica. Entre sus últimas publicaciones destacan: "Desarrollo local y los ambientes locales de innovación en el contexto regional; revisión de literatura y algunas preguntas de investigación" en Miroslawa Czerny y Jorge Tapia 
Quevedo (coords.), Regionalidad y localidad en la globalización, Wydawnictwa Uniwersytetu Warszawskiego, Varsovia, pp. 77-102 (2007); "Acapulco, redes y competitividad: un recorrido geohistórico de tres zonas turísticas", en Álvaro Sánchez Crispín (comp.), Geografía y procesos territoriales en el estado de Guerrero, Universidad Autónoma de GuerreroSociedad Mexicana de Geografía y Estadística, Chilpancingo, pp. 238-260 (2008). 